\title{
Understanding the performance of the FLake model over two African Great Lakes
}

\author{
W. Thiery ${ }^{1}$, A. Martynov ${ }^{2,3}$, F. Darchambeau ${ }^{4}$, J.-P. Descy ${ }^{5}$, P.-D. Plisnier ${ }^{6}$, L. Sushama ${ }^{2}$, and N. P. M. van Lipzig ${ }^{1}$ \\ ${ }^{1}$ Department of Earth and Environmental Sciences, University of Leuven, Leuven, Belgium \\ ${ }^{2}$ Centre pour l'Étude et la Simulation du Climat à l'Échelle Régionale (ESCER), Université du Québec à Montréal, \\ Montréal, Canada \\ ${ }^{3}$ Institute of Geography and Oeschger Centre for Climate Change Research, University of Bern, Bern, Switzerland \\ ${ }^{4}$ Unité d'Océanographie Chimique, Université de Liège, Liège, Belgium \\ ${ }^{5}$ Laboratoire d'écologie des Eaux Douces, University of Namur, Namur, Belgium \\ ${ }^{6}$ Royal Museum for Central Africa, Tervuren, Belgium \\ Correspondence to: W. Thiery (wim.thiery@ees.kuleuven.be)
}

Received: 25 July 2013 - Published in Geosci. Model Dev. Discuss.: 2 October 2013

Revised: 14 January 2014 - Accepted: 15 January 2014 - Published: 18 February 2014

\begin{abstract}
The ability of the one-dimensional lake model FLake to represent the mixolimnion temperatures for tropical conditions was tested for three locations in East Africa: Lake Kivu and Lake Tanganyika's northern and southern basins. Meteorological observations from surrounding automatic weather stations were corrected and used to drive FLake, whereas a comprehensive set of water temperature profiles served to evaluate the model at each site. Careful forcing data correction and model configuration made it possible to reproduce the observed mixed layer seasonality at Lake Kivu and Lake Tanganyika (northern and southern basins), with correct representation of both the mixed layer depth and water temperatures. At Lake Kivu, mixolimnion temperatures predicted by FLake were found to be sensitive both to minimal variations in the external parameters and to small changes in the meteorological driving data, in particular wind velocity. In each case, small modifications may lead to a regime switch, from the correctly represented seasonal mixed layer deepening to either completely mixed or permanently stratified conditions from $\sim 10 \mathrm{~m}$ downwards. In contrast, model temperatures were found to be robust close to the surface, with acceptable predictions of near-surface water temperatures even when the seasonal mixing regime is not reproduced. FLake can thus be a suitable tool to parameterise tropical lake water surface temperatures within atmospheric prediction models. Finally, FLake was used to attribute the seasonal mixing cycle at Lake Kivu to variations
\end{abstract}

in the near-surface meteorological conditions. It was found that the annual mixing down to $60 \mathrm{~m}$ during the main dry season is primarily due to enhanced lake evaporation and secondarily to the decreased incoming long wave radiation, both causing a significant heat loss from the lake surface and associated mixolimnion cooling.

\section{Introduction}

Owing to the strong contrast in albedo, roughness and heat capacity between land and water, lakes significantly influence the surface-atmosphere exchange of moisture, heat and momentum (Bonan, 1995; Mironov et al., 2010). Some effects of this modified exchange are (i) the dampening of the diurnal temperature cycle and lagged temperature response over lakes compared to adjacent land, (ii) enhanced winds due to the lower surface roughness, (iii) higher moisture input into the atmosphere as lakes evaporate at the potential evaporation rate, and (iv) the formation of local winds, such as the lake/land breezes (Savijärvi and Järvenoja 2000; Samuelsson et al., 2010; Lauwaet et al., 2011).

One such region where lakes are a key component of the climate system is the African Great Lakes region. During last decades, the African Great Lakes experienced fast changes in ecosystem structure and functioning, and their future evolution is a major concern (O'Reilly et al., 2003; Verburg et 
al., 2003; Verburg and Hecky, 2009). To better understand the present lake hydrodynamics and their relation to aquatic chemistry and biology, several comprehensive one-, two- or three-dimensional hydrodynamic models have been developed and applied in standalone mode to lakes in this region (Schmid et al., 2005; Naithani et al., 2007; Gourgue et al., 2011; Verburg et al., 2011). However, to investigate the two-way interactions between climate and lake processes over East Africa, a correct representation of lakes within regional climate models (RCMs) and general circulation models (GCMs) is essential (Stepanenko et al., 2013; see Appendix for a list of all acronyms, variables and simulation names). For now, the high computational expense of complex hydrodynamic lake models limits the applicability of coupled lake-atmosphere model systems to process studies (Anyah et al., 2006; Thiery et al., 2014). To overcome this issue, the Freshwater Lake model (FLake) was recently developed (Mironov, 2008; Mironov et al., 2010). It offers a very good compromise between physical realism and computational efficiency.

As a one-dimensional lake parameterisation scheme, FLake has already been coupled to a large number of numerical weather prediction (NWP) systems, RCMs and GCMs (Kourzeneva et al., 2008; Dutra et al., 2010; Mironov et al., 2010; Salgado and Le Moigne, 2010; Samuelsson et al., 2010; Martynov et al., 2012). However, even though it has become a landmark in this respect, FLake has never been thoroughly tested for tropical conditions. Moreover, as several joint efforts to provide society with climate change information, such as the COordinated Regional climate Downscaling EXperiment (CORDEX), explicitly focus on the African continent (Giorgi et al., 2009), a correct representation of the African Great Lakes within NWP, RCMs and GCMs becomes of particular importance.

Hence, the main goal of this study is to test - for the first time - the ability of FLake to reproduce the temperature regimes of two tropical lakes in East Africa. Lake Kivu and Lake Tanganyika are selected, as they are the only rift lakes for which both local weather conditions and lake water temperatures have been monitored for several years. Lake Kivu (Fig. 1b), is a deep meromictic lake, with an oxic mixolimnion seasonally extending down to $60-70 \mathrm{~m}$, below which the monimolimnion is found rich in nutrients and dissolved gases, in particular carbon dioxide and methane (Fig. 2; Degens et al., 1973; Borgès et al., 2011; Descy et al., 2012). Due to the input of heat and salts from deep geothermal springs, temperature and salinity in the monimolimnion increase with depth (Degens et al., 1973; Spigel and Coulter, 1996; Schmid et al., 2005). Moreover, in the deeper layers, vertical diffusive transport is dominated by double diffusive convection (Schmid et al., 2010). Lake Tanganyika (Fig. 1c), the first Albertine rift lake south of Lake Kivu, stretches $670 \mathrm{~km}$ southwards and, with its $60 \mathrm{~km}$ mean width and maximum depth of $1470 \mathrm{~m}$, represents the second largest surface freshwater reservoir on earth $\left(18880 \mathrm{~km}^{3}\right.$; Savijärvi,
1997; Alleman et al., 2005; Verburg and Hecky, 2009). Lake Tanganyika is also meromictic (Naithani et al., 2007), but its salt content is lower compared to Lake Kivu (Spigel and Coulter, 1996). Lake Kivu and Lake Tanganyika are both characterised by long lake water retention times $(\sim 100 \mathrm{yr}$ and $\sim 800$ yr, respectively; Schmid and Wüest, 2012; Coulter, 1991), hence the impact of riverine in- and outflow is of little importance to the circulation within these lakes.

In this study, lake temperatures were calculated for three sites, one at Lake Kivu and two at Lake Tanganyika, by forcing FLake with observations from surrounding automatic weather stations (AWSs) and subsequently comparing them to observed time series. Besides integrating them with the raw meteorological observations, wind speed measurements and water transparency were also refined within their uncertainty range to yield a control simulation representing the correct mixing regime. At each location, FLake was also driven by the re-analysis product ERA-Interim (Simmons et al., 2007). Furthermore, a systematic analysis of FLake's sensitivity to variations in external parameters, meteorological forcing data, and temperature initialisation was conducted. Finally, a study of the surface energy balance allowed attributing the mixing regime at Lake Kivu to changes in nearsurface meteorological conditions.

\section{Data and methods}

\subsection{AWS data}

The Lake Kivu region is characterised by a long dry season extending from June to September, and a wet season from October to May, interrupted by a short dry season around January (Beadle, 1981). Further south in Lake Tanganyika, the dry season sets in one month earlier (Spigel and Coulter, 1996; Verburg and Hecky, 2003). Over both lakes, predominantly southeasterly winds reach a maximum during the dry season (Nicholson, 1996; Verburg and Hecky, 2003; Sarmento et al., 2006).

AWS 1 is located on the roof of the Institut Supérieur Pédagogique in Bukavu, Democratic Republic of the Congo, approximately $1 \mathrm{~km}$ from the southern border of Lake Kivu and $27 \mathrm{~km}$ southwest from the monitoring site in the Ishungu Basin (Fig. 1b). For this study, meteorological observations covering a period of $9 \mathrm{yr}$ (2003-2011) were used. AWS 2 is situated at the Tanzania Fisheries Research Institute in Kigoma, Tanzania, $50 \mathrm{~m}$ from the lake shore and $4 \mathrm{~km}$ southeast from the evaluation site in Kigoma (Fig. 1c). As such, this station recorded meteorological conditions representative for the northern Tanganyika Basin from 2002 to 2006. Finally, considered as representative for the southern Tanganyika Basin, AWS 3 is located at Mpulungu Department of Fisheries, on the lake shore and $8.5 \mathrm{~km}$ south of the monitoring site of Mpulungu (Fig. 1c). Unfortunately, for this station only 13 months of data (February 2002-April 2003) were 


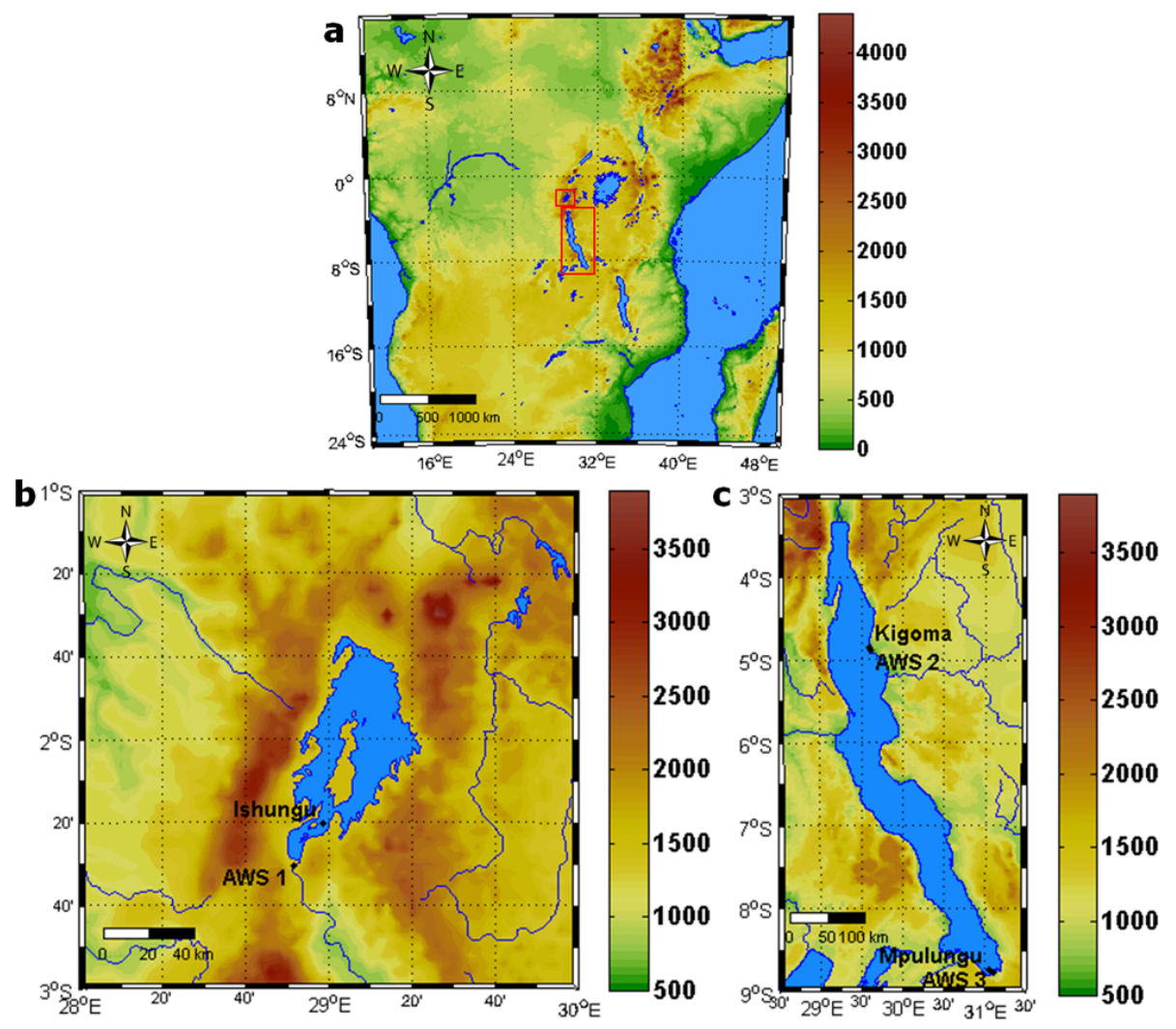

Fig. 1. (a) overview of East Africa with rectangles around Lake Kivu (upper) and Lake Tanganyika (lower), (b) Lake Kivu, (c) Lake Tanganyika. Surface altitude is shown in ma.s.l.

available. With all three AWSs located on land, one can expect some differences between the measured values and actual meteorological conditions at the sites they aim to represent. However, given the lack of meteorological observations at these locations, it is difficult to assess the degree to which these stations represent their respective evaluation site, except probably for wind speed measurements (Sect. 2.4). Possibly AWS 3, the most exposed station and located on the lake shore, succeeds best at representing the meteorological conditions of the evaluation site. AWS topographic characteristics and meteorological averages are listed in Table 1.

Each AWS records air temperature $(T)$, pressure $(p)$, wind speed $(f f)$ and direction $(d d)$, relative humidity (RH) and downward short-wave radiation $\left(\mathrm{SW}_{\mathrm{in}}\right)$ at a single level above the surface, and at an estimated accuracy of $\pm 0.5^{\circ} \mathrm{C}, \pm 1 \mathrm{hPa}, \pm 5 \%, \pm 3^{\circ}, \pm 3 \%$ and $\pm 5 \%$, respectively. The measurement frequency is $30 \mathrm{~min}$ at AWS 1 and 15 min at AWS 2 and 3, but for the integrations only hourly instantaneous values were retained. Three problems needed to be overcome to prepare the forcing data for the FLake simulations. First, all stations experience frequent data gaps (50\%, $23 \%$ and $37 \%$ of the time at AWS 1, 2 and 3, respectively), and gaps are too long to be filled using simple interpolation techniques. This issue was solved by calculating for each hour of the year the climatological average from available observations and subsequently filling all data gaps with the corresponding climatological value. When no climatological value is available for $\mathrm{SW}_{\mathrm{in}}$, the value of the previous day was used. At AWS 3, where the time series is too short to obtain climatological values, data gaps were instead filled by the average daily cycle. Second, time series of downward long-wave radiation $\left(\mathrm{LW}_{\text {in }}\right)$, a necessary forcing variable to FLake, are not measured by the AWSs. Hence, they were retrieved from the ERA-Interim grid point closest to the evaluation site and subsequently converted from 6-hourly accumulated values to hourly instantaneous value.

\subsection{FLake model}

The one-dimensional FLake model is designed to represent the evolution of a lake column temperature profile and the integral energy budgets of its different layers (Mironov, 2008; Mironov et al., 2010). In particular, the model consists of two vertical water layers: a mixed layer, which is assumed to have a uniform temperature $\left(T_{\mathrm{ML}}\right)$, and an underlying thermocline, extending down to the lake bottom (Fig. 2). The temperature-depth curve in the thermocline is parameterised through the concept of self-similarity, or assumed-shape (Kitaigorodskii and Miropolskii, 1970), meaning that the characteristic shape of the temperature profile is conserved 
Table 1. Automatic Weather Station (AWS) topographic and meteorological characteristics.

\begin{tabular}{llll}
\hline & AWS 1 & AWS 2 & AWS 3 \\
\hline Location & & & \\
\hline Corresponding evaluation site & Ishungu & Kigoma & Mpulungu \\
Latitude & $2^{\circ} 30^{\prime} 27^{\prime \prime} \mathrm{S}$ & $4^{\circ} 53^{\prime} 15^{\prime \prime} \mathrm{S}$ & $8^{\circ} 45^{\prime} 59^{\prime \prime}$ \\
Longitude & $28^{\circ} 51^{\prime} 27^{\prime \prime} \mathrm{E}$ & $29^{\circ} 37^{\prime} 11^{\prime \prime} \mathrm{E}$ & $31^{\circ} 6^{\prime} 25^{\prime \prime}$ \\
Altitude (m a.s.l.) & 1570 & 777 & 782 \\
\hline Set-up of this study & & & \\
\hline Start of observation & 1 Jan 2003 & 1 Jan 2002 & 2 Feb 2002 \\
End of observation & $31 \mathrm{Dec} 2011$ & $31 \mathrm{Dec} 2006$ & $4 \mathrm{Apr} 2003$ \\
\hline Meteorological averages, after corrections & & \\
\hline$T\left({ }^{\circ} \mathrm{C}\right)$ & 19.4 & 24.5 & 24.1 \\
RH $(\%)$ & 76 & 70 & 58 \\
$f f\left(\mathrm{~m} \mathrm{~s}{ }^{-1}\right.$ ) & 1.9 & 0.3 & 2.6 \\
\hline
\end{tabular}

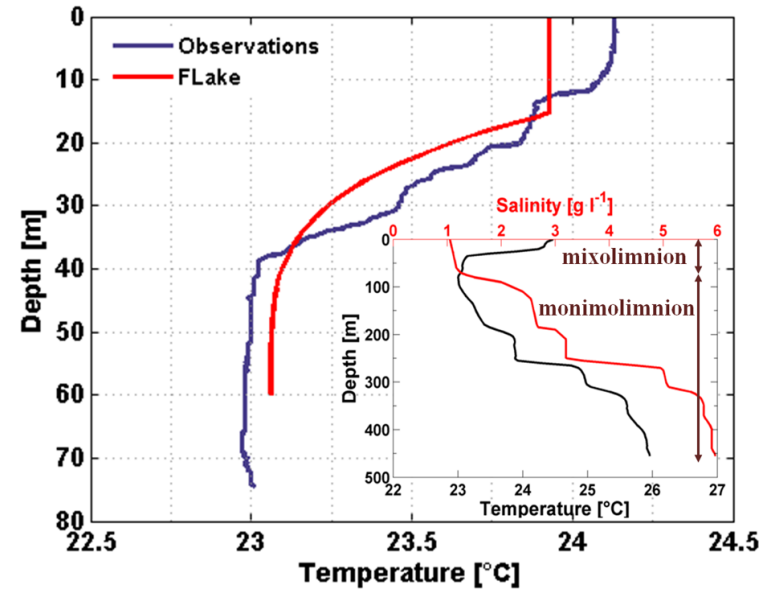

Fig. 2. Water temperature recorded at Ishungu on 21 April 2009 and corresponding FLake midday temperature profile, the latter with its distinct two-layer structure (mixed layer and thermocline). Inset: temperature (black) and salinity (red) profile representative for the main basin during February 2004, as reported by Schmid et al. (2005). For Lake Kivu, the artificial lake depth set in FLake corresponds to the mixolimnion depth, hence the monimolimnion has no counterpart in FLake. Note the strong increase in salinity from 60-70 $\mathrm{m}$ downwards, i.e. below the mixolimnion.

irrespective of the depth of this layer (Munk and Anderson, 1948). Hence, within the thermocline, temperature at a relative (dimensionless) depth within the thermocline depends only on the shape of the thermocline curve. In turn, this shape is determined only by the temperature at the top and bottom of the thermocline and by a shape factor, describing the curve through a fourth-order polynomial (Mironov, 2008). Additionally, FLake includes the representation of the thermal structure of lake ice and snow cover and (optionally) also of the temperature of two layers in the bottom sediments, all using the concept of self-similarity. Without considering ice/snow cover and bottom sediments, the prognostic variables computed by the model reduce to: the mixed layer depth $\left(h_{\mathrm{ML}}\right)$, the bottom temperature $\left(T_{\mathrm{BOT}}\right)$, the water column average temperature $\left(T_{\mathrm{MW}}\right)$ and the shape factor with respect to the temperature profile in the thermocline $\left(C_{T}\right)$. The mixed layer depth is calculated including effects of both convective and mechanical mixing, while volumetric heating is accounted for through the net short-wave radiation penetrating the water and becoming absorbed according to the Beer-Lambert law (Mironov, 2008; Mironov et al., 2010). Finally, along with the standalone FLake model comes a set of surface flux subroutines originating from the limited-area atmospheric model COSMO (Consortium for Small-scale Modeling; Doms and Schättler, 2002), hence the components of the surface energy balance are computed following the method described by Raschendorfer (2001; see also Doms et al., 2011; Akkermans et al., 2012).

The approach adopted in this study is to test FLake version 1 as close as possible to its native configuration, i.e. how it is operationally used as a lake parameterisation scheme within most atmospheric prediction models. Consequently, modifications in the source code from which the predictions would potentially benefit, such as including time-dependent water transparency, making the distinction between the visible and near-infrared fractions of $\mathrm{SW}_{\text {in }}$ (each with their own absorption characteristics), improving the parameterisation of the thermocline's shape factor, defining a geothermal heat flux, accounting for the effect of bottom sediments, and including an abyssal layer or diurnal stratification, were not taken into account in this study. Conversely, some of these effects were considered during the lake model intercomparison experiment for Lake Kivu (Thiery et al., 2014). 


\subsection{Water transparency and temperature profiles}

In oligotrophic environments such as Lake Tanganyika and Kivu, water transparency is predominantly related to phytoplankton development, which is usually confirmed by a good correlation between the chlorophyll $a$ concentrations and the downward light attenuation coefficient $k\left(\mathrm{~m}^{-1}\right)$ or related quantity (Naithani et al., 2007; Darchambeau et al., 2014). In FLake, however, $k$ has to be ascribed a constant value. A large measurement set of disappearance depths of the Secchi disk $z_{\mathrm{sd}}(\mathrm{m})$ are available for each site (Table 2). $z_{\mathrm{sd}}$ were converted to $k$ using the relationship

$k=\frac{-\ln (0.25)}{z_{\mathrm{sd}}}$,

where 0.25 refers to the fraction of incident radiation penetrating to the depth at which the Secchi disk is no longer visible. This fraction, differing from one Secchi disk to another, was retrieved at Lake Kivu by means of 15 simultaneous measurements of $z_{\mathrm{sd}}$ and the vertical profile of light conditions using a LI-193SA Spherical Quantum Sensor, from which $k$ was estimated. For each data set of $k$, a gamma probability density function was fitted (Fig. 3), from which subsequently average $\bar{k}$ and standard deviation $\sigma_{k}$ were calculated (Table 2). The higher $\bar{k}$ observed at Ishungu relative to Kigoma and Mpulungu is caused by the higher phytoplankton biomass (represented by chlorophyll $a$ concentrations) in Lake Kivu ( $2.02 \pm 0.78 \mathrm{mg} \mathrm{m}^{-3}$; Sarmento et al., 2012) compared to Lake Tanganyika $\left(0.67 \pm 0.25 \mathrm{mg} \mathrm{m}^{-3}\right.$; Stenuite et al., 2007). Note that, since an uncertainty remains associated with the exact value of $k$, its value was allowed to vary within given bounds in the different simulations (see Sect. 2.4).

The evaluation of the FLake simulations was made by the use of 419 conductivity-temperature-depth (CTD) casts collected at Ishungu (Lake Kivu), Kigoma (Lake Tanganyika's northern basin) and Mpulungu (Lake Tanganyika's southern basin; Table 2). At each of these locations, they provide a clear image of the surface lake's thermal structure and hence mixing regime. While it can be argued that temperature recordings at Ishungu are representative for the whole of Lake Kivu, except Bukavu Bay and Kabuno Bay (Thiery et al., 2014), the same cannot be claimed for Lake Tanganyika, where seasonal variations in wind velocity and internal wave motions cause spatially variant mixing dynamics (Plisnier et al., 1999). This is also apparent from the comparison of the CTD casts of Kigoma and Mpulungu (Sects. 3.2 and 3.3). Consequently, the results of the FLake simulations for Ishungu can be used to study the mixing physics of Lake Kivu (Sect. 3.6), whereas the mixing processes within the whole of Lake Tanganyika cannot be captured by singlecolumn simulations at two sites only.

To ease the intercomparison of the different CTD casts, first, each temperature profile was spatially interpolated to a regular vertical grid with increment $0.1 \mathrm{~m}$ using the piecewise cubic Hermite interpolation technique (De Boor, 1978).

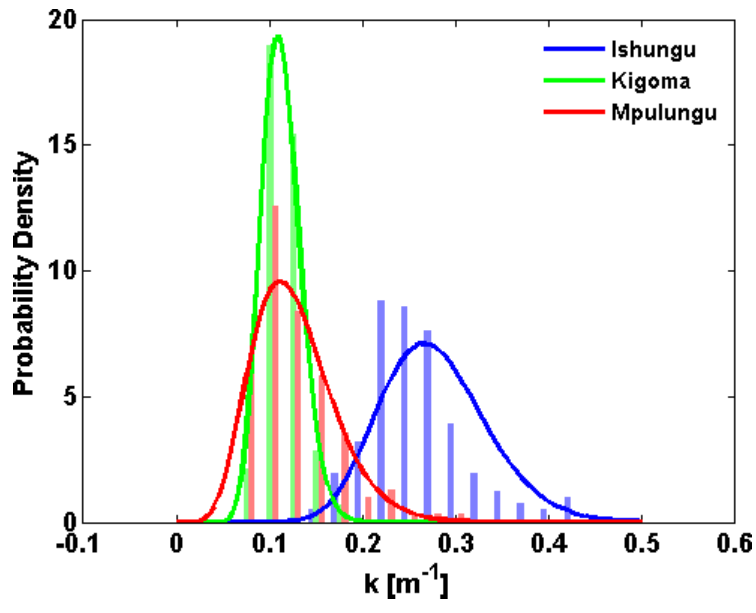

Fig. 3. Comparative histogram of the downward light attenuation coefficient $k\left(\mathrm{~m}^{-1}\right)$ as observed at Ishungu Basin (Lake Kivu) and Kigoma and Mpulungu stations (Lake Tanganyika). Gamma distribution probability density functions are plotted to the data ( $R^{2}=0.82,0.99$ and 0.93 for Ishungu, Kigoma and Mpulungu, respectively).

Subsequently, the depth of the mixed layer was determined for each cast as the depth with the maximum downward temperature change per metre lower than a predefined threshold $\left(-0.03{ }^{\circ} \mathrm{C} \mathrm{m}^{-1}\right)$. Whenever the thermal gradient did not exceed this threshold, the lake was assumed to be mixed down to the artificial model depth (see Sect. 2.4). Finally, both temperature profiles and mixed layer depths were also temporally interpolated to a grid with increment of one day using the same spline interpolation.

\subsection{Model configuration, evaluation and sensitivity}

Both in situ meteorological measurements and ERA-Interim data from the nearest grid cell were used to drive FLake in standalone mode (decoupled from an atmospheric model) for three different locations: Ishungu, Kigoma and Mpulungu (Fig. 1). One of FLake's main external parameters is the lake depth (Mironov, 2008; Kourzeneva et al., 2012b). However, for most of the deep African Great Lakes, their actual lake depth cannot be used, since FLake only describes the mixed layer and thermocline, whereas in reality a monimolimnion is found below the thermocline of these meromictic lakes. Consequently, an artificial model lake depth was defined at the maximum depth for which the observed temperature range exceeds $1{ }^{\circ} \mathrm{C}$ during the measurement period. When applying this criterion to the vertically interpolated temperature profiles, it was found that $60 \mathrm{~m}$ is an appropriate artificial depth for Lake Kivu, while for both basins of Lake Tanganyika the seasonal temperature cycle penetrates down to a depth of $100 \mathrm{~m}$. Note that for Lake Kivu, this depth coincides with the onset of the salinity increase, which inhibits deeper mixing (Fig. 2). As a consequence of using an artificial lake depth, 
Table 2. Characteristics of the model evaluation sites. Water transparency characteristics are the downward light attenuation coefficient $k$ $\left(\mathrm{m}^{-1}\right)$ and its standard deviation $\sigma_{k}\left(\mathrm{~m}^{-1}\right)$. Control run scores are standard deviation $\sigma_{T}\left({ }^{\circ} \mathrm{C}\right)$, centred root mean square error $\left(\mathrm{RMSE} \mathrm{E}_{\mathrm{c}}\right)$ $\left({ }^{\circ} \mathrm{C}\right)$, Pearson correlation coefficient $r$ and Brier Skill Score (BSS).

\begin{tabular}{lrrr}
\hline & Ishungu & Kigoma & Mpulungu \\
\hline General characteristics & & & \\
\hline Lake & Kivu & Tanganyika (northern basin) & Tanganyika (southern basin) \\
Latitude & $2^{\circ} 20^{\prime} 25^{\prime \prime} \mathrm{S}$ & $4^{\circ} 51^{\prime} 16^{\prime \prime} \mathrm{S}$ & $8^{\circ} 43^{\prime} 59^{\prime \prime} \mathrm{S}$ \\
Longitude & $28^{\circ} 58^{\prime} 36^{\prime \prime} \mathrm{E}$ & $29^{\circ} 35^{\prime} 32^{\prime \prime} \mathrm{E}$ & $31^{\circ} 2^{\prime} 26^{\prime \prime} \mathrm{E}$ \\
Altitude (m a.s.l.) & 1463 & 768 & 768 \\
Depth $(\mathrm{m})$ & 120 & 600 & 120 \\
Number of CTD casts & 174 & 119 & 126 \\
\hline Water transparency & & & 124 \\
\hline Number of Secchi depths & 163 & 114 & 0.13 \\
Average $k\left(\mathrm{~m}^{-1}\right)$ & 0.28 & 0.11 & 0.05 \\
$\sigma_{k}\left(\mathrm{~m}^{-1}\right)$ & 0.06 & 0.02 & 0.06 \\
Minimum $k\left(\mathrm{~m}^{-1}\right)$ & 0.15 & 0.07 & 0.31 \\
Maximum $k\left(\mathrm{~m}^{-1}\right)$ & 0.46 & 0.17 & \\
\hline Vertically averaged scores for control run & & & 0.67 \\
\hline$\sigma_{T}\left({ }^{\circ} \mathrm{C}\right)$ & 0.30 & 0.70 & 0.65 \\
$\left(\right.$ relative to $\sigma_{T, \text { obs }}\left({ }^{\circ} \mathrm{C}\right)$ & 0.32 & 0.49 & 0.89 \\
RMSE & $\left({ }^{\circ} \mathrm{C}\right)$ & 0.59 & 0.05 \\
$r$ & 0.22 & 0.51 & 1.81 \\
BSS & 0.71 & -93 & \\
\hline
\end{tabular}

the bottom sediments module was switched off in all simulations. Therewith, a zero heat flux assumption was adopted at the bottom boundary.

At each location, three simulations were conducted. First, FLake was integrated with observed meteorological values and using the average observed value for $k$ (hereafter referred to as "raw"). However, due to the location of AWS 1 and 2 - both surrounded by several buildings and large trees - especially the wind speed values are expected to be underestimated by these stations. Moreover, as the data gapfilling technique averaged out high values for $f f$, unrecorded high wind speed events were not recreated. Consequently, wind speed recordings at these stations can be considered as a lower bound for the actual $f f$ at the respective evaluation sites. As a supplementary evidence, wind velocity measurements from a state-of-the-art AWS, newly installed over the lake surface on a floating platform in the main basin and $2 \mathrm{~km}$ off the shoreline (AWS Kivu: $1^{\circ} 43^{\prime} 30^{\prime \prime} \mathrm{S}$, $29^{\circ} 14^{\prime} 15^{\prime \prime} \mathrm{E}$ ), showed that wind speeds at AWS Kivu were on average $2.0 \mathrm{~m} \mathrm{~s}^{-1}$ higher compared to AWS 1 (from October to November 2012, $n=892$, root mean square error $\mathrm{RMSE}=2.7 \mathrm{~m} \mathrm{~s}^{-1}$ ). By applying a constant increase of $2.0 \mathrm{~m} \mathrm{~s}^{-1}$ to the wind velocities observed at AWS 1, the RMSE between wind velocities from both AWSs reduced to $1.8 \mathrm{~m} \mathrm{~s}^{-1}$. Since the location of AWS Kivu is much more exposed than the Ishungu Basin - especially given the predominance of southeasterlies over the lake - wind velocities measured by AWS Kivu provide a definite upper bound for wind velocities in the Ishungu Basin. Hence, a second AWSdriven simulation was conducted wherein wind velocities were allowed to vary within specific upper (from AWS Kivu) and lower (from AWS 1) bounds until the observed mixing regime is reproduced $\left(0.1 \mathrm{~m} \mathrm{~s}^{-1}\right.$ increment; see Sect. 3.5.2 for another important argument in support of this operation). It was found that at Ishungu, increasing all $f f$ by $1.0 \mathrm{~m} \mathrm{~s}^{-1}$ resulted in a correct representation of the mixing regime (Sect. 3.1), whereas at Kigoma, ff had to be increased by $2.0 \mathrm{~m} \mathrm{~s}^{-1}$ (Sect. 3.2). At Mpulungu, where the driving AWS is located close by the evaluation site and on the lake shore, the correct mixing regime is already reproduced by the raw integration, and hence no wind speed correction needed to be applied (Sect. 3.3). After correcting for the wind speed, $k$ was varied iteratively between bounds $\bar{k}-\sigma_{k}$ and $\bar{k}+\sigma_{k}$ until the best values for the set of model efficiency scores were obtained (see below; hereafter referred to as "control"). This operation led to values of $0.32 \mathrm{~m}^{-1}, 0.10 \mathrm{~m}^{-1}$ and $0.09 \mathrm{~m}^{-1}$ for $k$ at Ishungu, Kigoma and Mpulungu, respectively. Note however that this second correction, restricted by $\sigma_{k}$ (Table 2), had little to no impact upon the final model outcome (At Ishungu, for instance, mean mixed layer and water column temperatures differ less than $0.001^{\circ} \mathrm{C}$ and $0.04^{\circ} \mathrm{C}$, respectively, after this second correction). 
Finally, FLake was integrated using ERA-Interim data from the nearest grid cell as forcing. ERA-Interim is a global reanalysis product produced by the European Centre for Medium-Range Weather Forecasts (ECMWF; Simmons et al., 2007). It consists of a long-term atmospheric model simulation in which historical meteorological observations are consistently assimilated. Note however that the horizontal resolution of this product is $\mathrm{T} 255\left(0.703125^{\circ}\right.$ or about $80 \mathrm{~km}$ ), hence a large fraction of each nearest pixel represents land instead of lake. Moreover, only few observations are assimilated into ERA-Interim over tropical Africa, adding to the uncertainty of this product as a source of meteorological input to FLake. At Mpulungu, the only site where this integration led to a correct representation of the mixing regime (Sect. 3.3), $k$ was again allowed to vary within bounds $\bar{k}-\sigma_{k}<k<\bar{k}+\sigma_{k}$, with $k=0.09 \mathrm{~m}^{-1}$ retained.

In each simulation, lake water temperatures were initialised by the average $T_{\mathrm{ML}}, T_{\mathrm{WM}}$ and $T_{\mathrm{BOT}}$ calculated from the linearly interpolated observed January temperature profiles ( $n=14,8$ and 10 at Ishungu, Kigoma and Mpulungu, respectively). Then, for each location the spin-up time was determined by repeatedly forcing the model with the atmospheric time series until the initial $T_{\mathrm{BOT}}$ remained constant. This approach was found to be preferable above a spinup with a constant forcing or with a climatological year (Mironov et al., 2010), as the averaging of the wind speed observations removes extremes which may trigger the deep mixing in these lakes. It was found that, depending on the location and for the control model configuration, a spin-up time from 9 to $330 \mathrm{yr}$ is needed before convergence is reached.

The ability of FLake to reproduce the observed temperature structure was tested by comparing FLake's near-surface and bottom temperature to the corresponding observed values at each location. Note that a depth of $5 \mathrm{~m}$ was chosen representative for the surface waters, since (i) CTD casts were generally collected around noon and temperatures in the first metres are therefore positively biased relative to the daily averages, and (ii) FLake does not fully account for the daytime surface stratification because the mixed layer has a uniform temperature. Furthermore, a set of four model efficiency scores was computed: the standard deviation $\sigma_{T}\left({ }^{\circ} \mathrm{C}\right)$, the centred root mean square error $\operatorname{RMSE}_{\mathrm{c}}\left({ }^{\circ} \mathrm{C}\right)$, the Pearson correlation coefficient $r$ and the Brier Skill Score BSS (Nash and Sutcliffe, 1970; Taylor, 2001; Wilks, 2005). The former three calculated scores are visualised together in a Taylor diagram (Taylor, 2001), enabling the performance assessment of FLake. The RMSE is given by

$\mathrm{RMSE}_{\mathrm{c}}=\sqrt{\frac{1}{N} \sum_{i=1}^{n}\left(\left(m_{i}-\bar{m}\right)-\left(o_{i}-\bar{o}\right)\right)^{2}}$,

while the BSS is computed according to
$\mathrm{BSS}=1-\frac{\sum_{i=1}^{n}\left(o_{i}-m_{i}\right)^{2}}{\sum_{i=1}^{n}\left(o_{i}-\bar{o}\right)^{2}}$,

with $o_{i}$ the observed (interpolated) water temperature, $\bar{o}$ the average observed water temperature, and $m_{i}$ and $\bar{m}$ the corresponding modelled values at time $i$. Values for BSS range from $-\infty$ (no relation between observed and predicted value) to +1 (perfect prediction). Note that, compared to the variables displayed in a Taylor diagram, the BSS has the advantage of accounting for the model bias.

The sensitivity of the model was evaluated by conducting a number of simulations, each with an alternative configuration. In particular, the effects of variations in the external parameter values, the driving data and the initial conditions were investigated in this sensitivity study. Depending on the nature of each sensitivity experiment, different scores are applied to quantify the effect of a specific modification. Details of the different experiments are outlined in Sect. 3.5.

\section{Results}

\subsection{Ishungu}

Comparing modelled and observed water temperatures of Lake Kivu near the surface $(5 \mathrm{~m})$ shows that the timing of the near-surface seasonal cycle is well represented by the raw, control and ERA-Interim simulations (Fig. 4a). However, whereas it shows a small negative bias compared to the observations, only the control integration grasps the correct magnitude of the seasonal temperature range. The overestimation of the temperature seasonality in the raw and ERAInterim simulations is reflected by $5 \mathrm{~m}$ BSS of -0.36 and -2.13 , respectively, compared to only -0.26 for the control case. At a depth of $60 \mathrm{~m}$, both the raw and ERA-Interim integration predict a year-round constant temperature of $3.98^{\circ} \mathrm{C}$, the temperature of maximum density, resulting in a cold bias of about $19^{\circ} \mathrm{C}$. At the bottom, the lake's thermal structure is reproduced only by the control simulation $(\mathrm{BSS}=-0.17$; Fig. 4b).

Once a year, during the dry season (from June to August), the mixed layer depth at Ishungu extends down to approximately $60 \mathrm{~m}$. At this depth, the upwelling of deep, saline waters $\left(0.5 \mathrm{~m} \mathrm{yr}^{-1}\right.$; Schmid and Wüest, 2012) equilibrates with mixing forces. The result is a strong salinity gradient from $60 \mathrm{~m}$ downwards (Fig. 2). During the remainder of the year, stratified conditions dominate, with the mixed layer depth varying between 10 and $30 \mathrm{~m}$ (Fig. 5a). The raw simulation does not reproduce this mixing seasonality, but instead predicts permanently stratified conditions and a complete cooling down to $3.98^{\circ} \mathrm{C}$ from $30 \mathrm{~m}$ downwards. On the other hand, with $f f$ corrected for the land effect and $k$ tuned to 

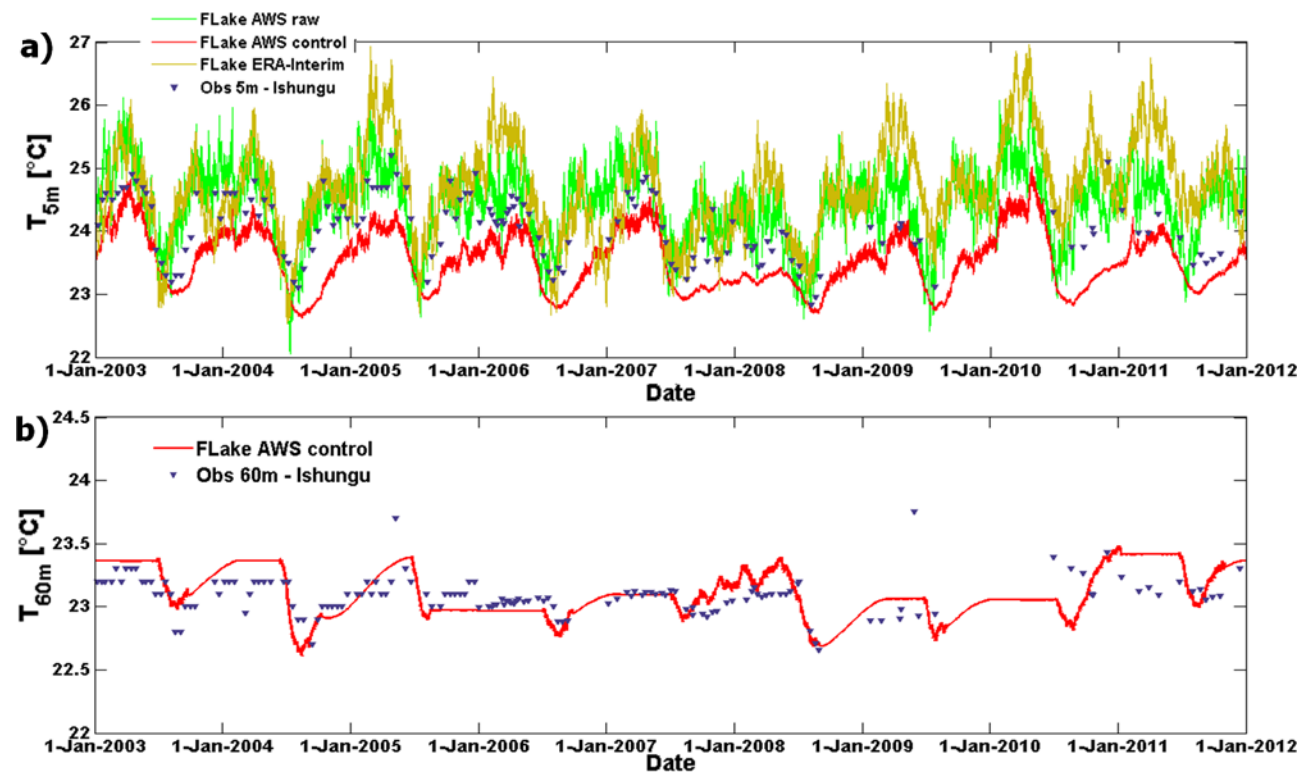

Fig. 4. Modelled and observed temperature evolution at Ishungu (Lake Kivu) at (a) $5 \mathrm{~m}$, and (b) $60 \mathrm{~m}$ depth. FLake temperatures at $60 \mathrm{~m}$ predicted by the raw and ERA-Interim integration are omitted as they are constant at $3.98^{\circ} \mathrm{C}$.

$0.32 \mathrm{~m}^{-1}$, the control simulation closely reproduces the mixing regime at Ishungu (Fig. 5b; Table 2). In this case, also the lower stability, indicated by the observations near the end of 2006 and during 2008 and 2009, is captured by this control simulation, although it is somewhat overestimated in 2008 with a predicted year-round mixing down to $\sim 55 \mathrm{~m}$. Note however that, due to the lower stability during these years, the effect on the near-surface water temperatures is limited. Furthermore, also the late onset of the stratification in early 2007 is represented by the model.

Finally, feeding FLake with ERA-Interim-derived nearsurface meteorology does not succeed in reproducing the mixing regime. Instead, this simulation predicts permanently stratified conditions and a complete cooling down to $3.98^{\circ} \mathrm{C}$, the temperature of maximum density, from $30 \mathrm{~m}$ downwards (Fig. 5c). The low and constant mixed layer depth generates near-surface temperature fluctuations found too strong on seasonal timescales (Fig. 4a). Similar to the raw integration, the inability of the ERA-Interim integration to produce deep mixing is primarily due to the predicted values for the wind velocity, which are $33 \%$ lower compared to the control run average wind velocity and $49 \%$ lower compared to wind speeds from AWS Kivu (measured over the lake surface during 59 days from October to November 2012). Underlying reasons for this deviation are (i) the fact that the lake surface covers only a fraction of the selected ERA-Interim grid box, and (ii) the higher uncertainty of this product in central Africa owing to the sparse observational data coverage in this region (Dee et al., 2011).

\subsection{Kigoma}

At Kigoma, the raw and ERA-Interim integrations both predict too high temperature seasonality in the near-surface water (Fig. 6a). On the other hand, the control experiment clearly displays improved skill at $5 \mathrm{~m}$, especially during 2004 and 2005. At depth, both the raw and ERA-Interim integrations obtain a constant $3.98^{\circ} \mathrm{C}$ and therewith strongly deviate from the observations (Fig. 6b). In return, the control simulation again captures the actual conditions much better, even though it slightly underestimates the seasonal temperature range and retains a positive bias between 0 and $2{ }^{\circ} \mathrm{C}$.

Contrary to Lake Kivu, in Lake Tanganyika salinityinduced stratification below $60 \mathrm{~m}$ is negligible and seasonal variations in near-surface meteorology are more pronounced (Sect. 3.4). Consequently, the seasonal mixed layer extends further down both during the dry and wet season (Fig. 7a), with mixing recorded down to even $150 \mathrm{~m}$ (Verburg and Hecky, 2003) and $300 \mathrm{~m}$ (Plisnier et al., 1999). Similar to Ishungu, also at Kigoma the raw simulation does not result in a correct representation of the mixing regime, but predicts permanent stratified conditions and a complete cooling along the thermocline. Again, upward correction of $f f$ by $2 \mathrm{~m} \mathrm{~s}^{-1}$ and reducing $k$ to a value of $0.09 \mathrm{~m}^{-1}$ brings the model to the correct mixing regime at Kigoma (Fig. 7b; Table 2). The ERA-Interim simulation predicts permanent stratification due to too low wind velocities (Fig. 7c). Note that in both the ERA-Interim and the raw simulations, decreasing $\mathrm{k}$ from $0.11 \mathrm{~m}^{-1}$ to $0.09 \mathrm{~m}^{-1}$ leads to a regime switch from permanent stratification directly to fully mixed conditions (down to the model lake depth), the latter associated with a strong positive temperature bias both near the surface and at depth. 

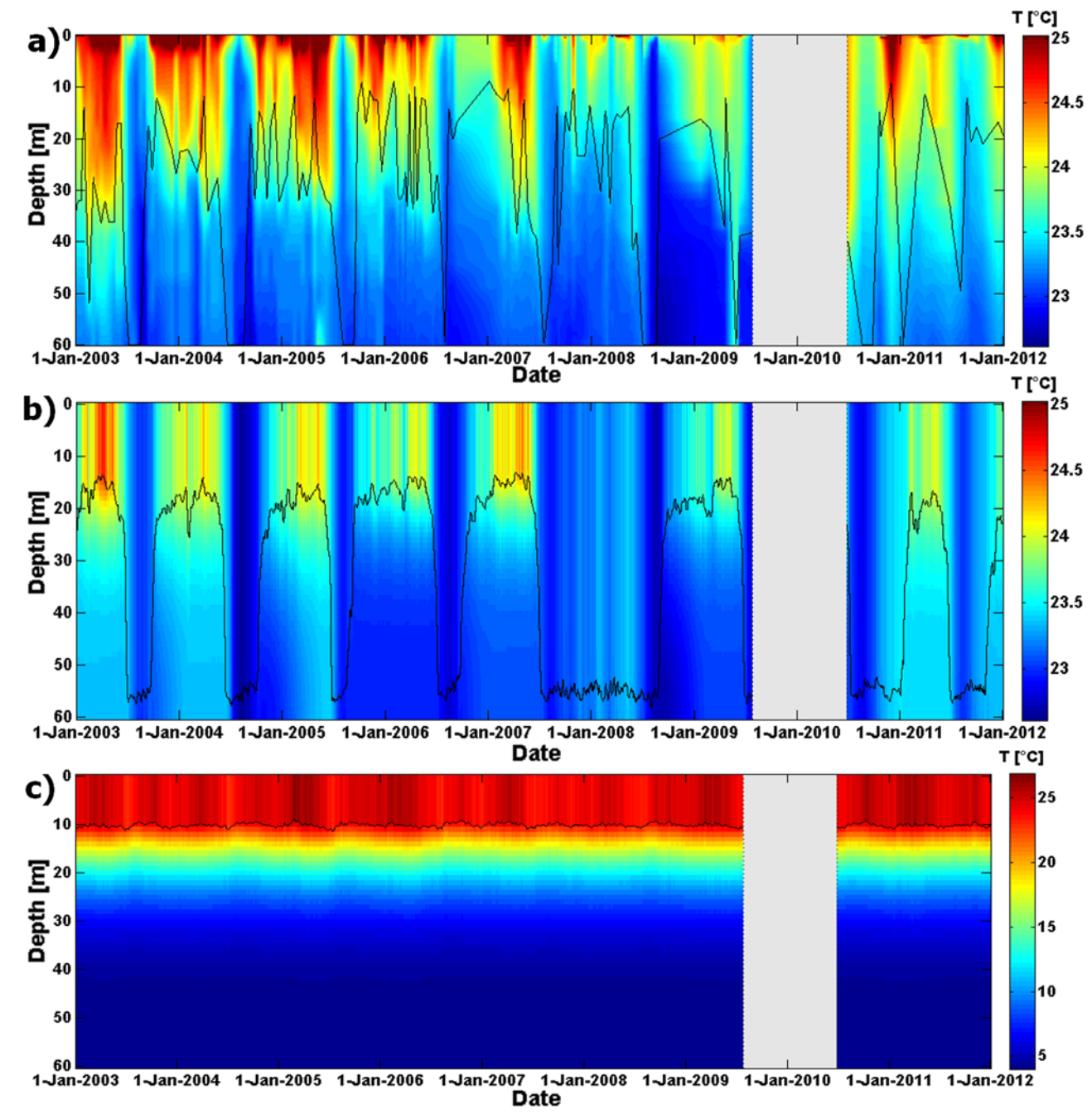

Fig. 5. Lake water temperatures $\left({ }^{\circ} \mathrm{C}\right)$ at Ishungu (Lake Kivu) (a) from observations, (b) as predicted by the AWS-driven FLake-control, and (c) as predicted by FLake-ERA-Interim. The black line depicts the mixed layer depth (Sect. 2.3; weekly mean for the simulations). Note the different colour scaling in (c). The lake water temperatures for the raw simulation are not shown as they strongly resemble the predictions of the ERA-Interim simulation.

\subsection{Mpulungu}

At Mpulungu, all three experiments capture the magnitude of the seasonal cycle in near-surface temperature and show little to no bias compared to the observations (Fig. 8a). However, also in each simulation the onset of complete mixing lags by around one month and lasts too long compared to observations (Fig. 8a). At $60 \mathrm{~m}$, a similar lag is found (Fig. 8b). Furthermore at this depth, the enhanced temperature seasonality of the control integration compared to the raw integration depicts its improved skill.

Although the FLake-AWS simulation at Mpulungu spans only 13 months, during this period two stratified periods and one fully mixed season are predicted by the model in both the raw $\left(k=0.13 \mathrm{~m}^{-1}\right)$ and control $\left(k=0.09 \mathrm{~m}^{-1}\right)$ set-up, in agreement with observations (Fig. 9a and b; Table 2). With
AWS 3 located on the lake shore (exposed) and relatively close to the evaluation site, no correction of $f f$ was necessary, and the mixing regime is correctly represented within the range $0.09 \mathrm{~m}^{-1}<k<0.22 \mathrm{~m}^{-1}$. Furthermore, also driving FLake with ERA-Interim at Mpulungu leads to a correct representation of the mixing regime (Fig. 9c).

From May to September, persistent southeasterly winds over Lake Tanganyika cause a tilting (downwards towards the north) of the mixolimnion-monimolimnion interface, and therewith generate the upwelling of deep, cold waters at the southern end of the lake (Plisnier et al., 1999). The resulting breakdown of the stratification appears through the absence of the thermocline at Mpulungu during the dry season (Fig. 9a), whereas at Kigoma, even during this period a weak thermocline remains present (Fig. 7a). Due to its self-similar, one-dimensional nature, FLake does not account for complex 

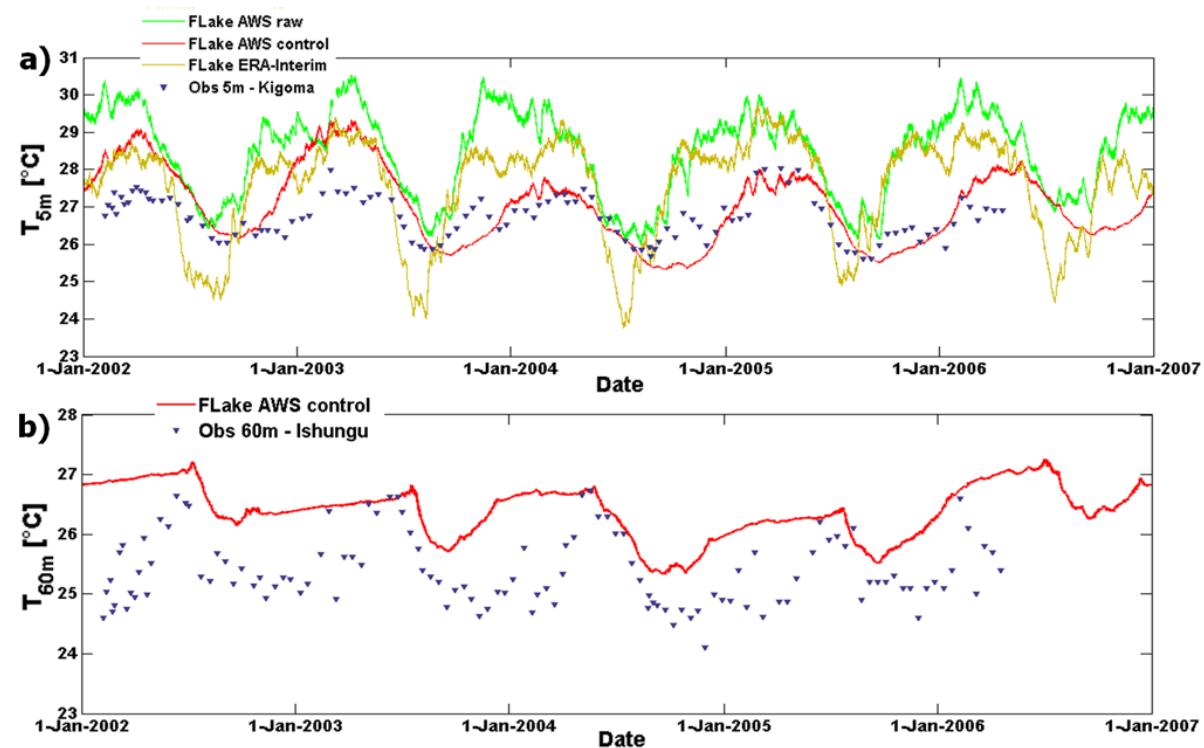

Fig. 6. Modelled and observed temperature evolution at Kigoma (northern basin of Lake Tanganyika) at (a) $5 \mathrm{~m}$, and (b) $60 \mathrm{~m}$ depth. FLake temperatures at $60 \mathrm{~m}$ predicted by the raw and ERA-Interim integration are omitted as they are constant at $3.98^{\circ} \mathrm{C}$.

hydrodynamic phenomena such as local upwelling and associated internal wave phenomena (Naithani et al., 2003), and therefore does not capture this difference between both sites (Figs. 7 and 9). It is likely that this phenomenon may also explain the time lag noticed in all Mpulungu simulations. The hydrodynamic response to the wind stress reinforces the seasonal cycle induced by lake-atmosphere interactions (Sect. 3.6): while the onset of the upwelling accelerates the cooling at the start of the dry season, a cessation of southeasterly winds in September generates the fast advection of warm mixolimnion waters from the north back towards Mpulungu, inducing a faster restoration of stratification than can be predicted by FLake from lake-atmosphere interactions alone.

\subsection{Comparison between sites}

A number of differences can be noted between the three locations. First, the average observed $5 \mathrm{~m}$ temperature is $2.6^{\circ} \mathrm{C}$ and $2.4^{\circ} \mathrm{C}$ lower in Ishungu (altitude $1463 \mathrm{~m}$ a.s.1.) compared to Kigoma and Mpulungu (altitude $768 \mathrm{~m}$ a.s.1.), respectively. Second, it can be observed that the water temperature seasonality increases with distance from the equator: at $5 \mathrm{~m}$, the maximal observed temperature ranges are $2.4^{\circ} \mathrm{C}, 2.5^{\circ} \mathrm{C}$ and $5.4^{\circ} \mathrm{C}$ in Ishungu, Kigoma and Mpulungu, respectively. This is related to differences in near-surface meteorology, since in the Southern Hemisphere at tropical latitudes, a higher distance from the equator coincides with a higher distance from the Intertropical Convergence Zone (ITCZ) during austral winter and thus creates a larger contrast between dry and wet season (Akkermans et al., 2014).
Third, although the average latent heat flux (LHF) is very similar at Ishungu $\left(88 \mathrm{~W} \mathrm{~m}^{-2}\right)$ and Kigoma $\left(86 \mathrm{~W} \mathrm{~m}^{-2}\right)$, it increases by $56 \%$ at Mpulungu $\left(134 \mathrm{~W} \mathrm{~m}^{-2}\right)$ during the respective measurement periods. Extrapolating the average LHF at Ishungu to the entire Lake Kivu surface (estimated by the control simulation and using a surface area of $2370 \mathrm{~km}^{2}$; Schmid and Wüest, 2012) leads to a preliminary estimate of the total annual evaporative flux of $2.6 \mathrm{~km}^{3} \mathrm{yr}^{-1}$ for the period 2003-2011. Note that, based on calculations from Bultot (1971), Schmid and Wüest (2012) estimate a total annual evaporation of $3.0-4.0 \mathrm{~km}^{3} \mathrm{yr}^{-1}$ for Lake Kivu. Analogously, extrapolating the average LHF computed for Kigoma to the northern Tanganyika Basin $\left(17572 \mathrm{~km}^{2}\right.$; Plisnier et al., 2007) leads to a preliminary estimate of $18.8 \mathrm{~km}^{3} \mathrm{yr}^{-1}$ for the total annual evaporation from the northern basin. At Mpulungu, where the control simulation predicts an average LHF of $133 \mathrm{~W} \mathrm{~m}^{-2}$ for the measurement period, extrapolation yields a total annual evaporation of $23.8 \mathrm{~km}^{3} \mathrm{yr}^{-1}$ from the southern basin $\left(14173 \mathrm{~km}^{2}\right.$; Plisnier et al., 2007). For the ERA-Interim simulations, the average LHF amounts up to $114 \mathrm{~W} \mathrm{~m}^{-2}\left(25.3 \mathrm{~km}^{3} \mathrm{yr}^{-1}\right)$ at Kigoma and $138 \mathrm{~W} \mathrm{~m}^{-2}$ $\left(24.7 \mathrm{~km}^{3} \mathrm{yr}^{-1}\right)$ at Mpulungu. Note that Verburg and Antenucci (2010) computed a lake-wide evaporation amounting up to $63 \mathrm{~km}^{3} \mathrm{yr}^{-1}$, when assuming a total surface area of $31745 \mathrm{~km}^{2}$ for Lake Tanganyika. The annual lake-wide evaporation estimates from the control and ERA-Interim simulations are only $65 \%\left(42.6 \mathrm{~km}^{3}\right)$ and $80 \%\left(50.1 \mathrm{~km}^{3}\right)$ of this value, respectively. Possible explanations for this discrepancy are (i) the different method used to compute the latent heat flux, (ii) differences in the quality and length of the meteorological time series, and (iii) the period of observation (1994-1996 versus 2002-2003 and 2002-2006, 

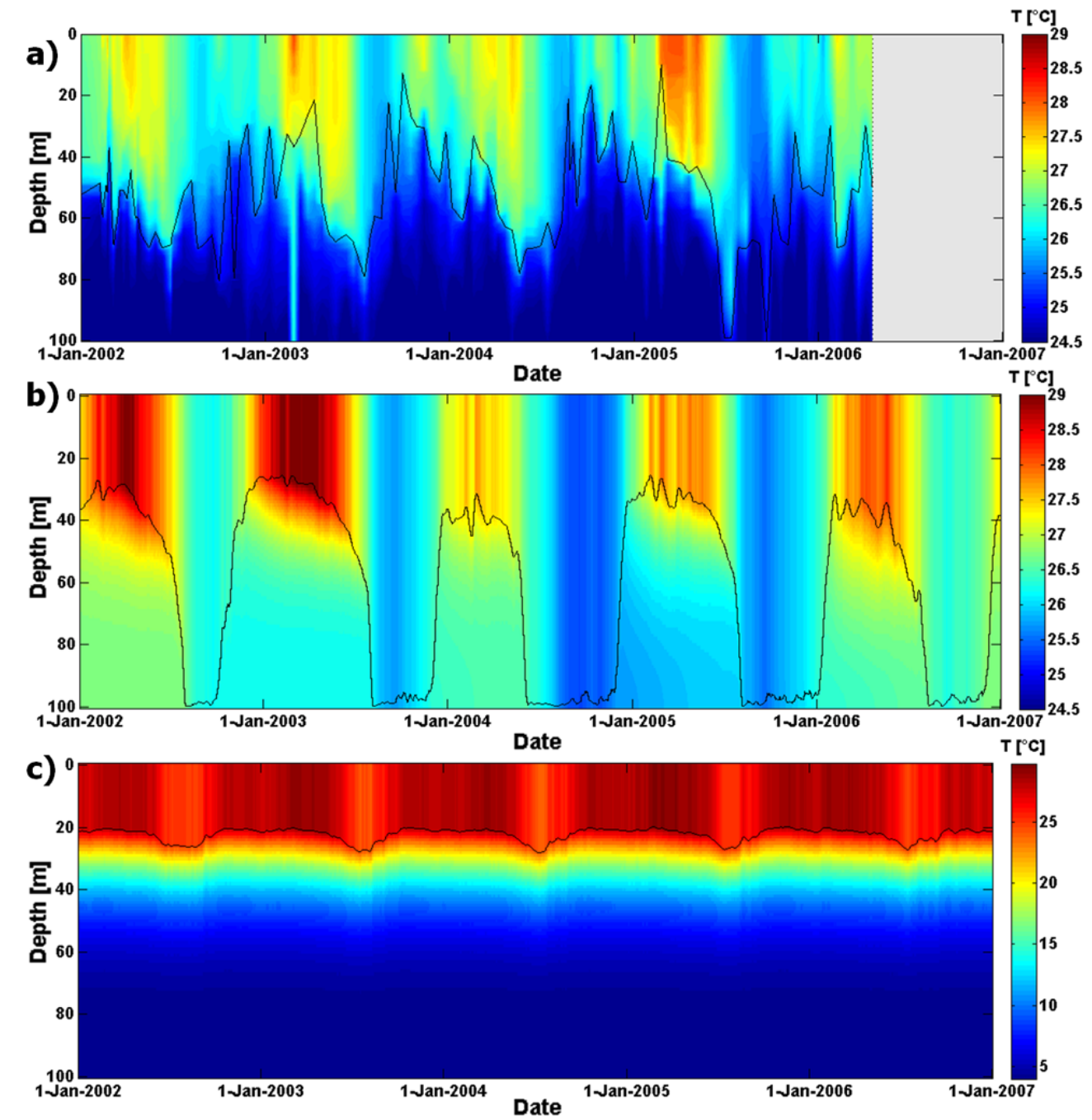

Fig. 7. Lake water temperatures $\left({ }^{\circ} \mathrm{C}\right)$ at Kigoma (northern basin of Lake Tanganyika) (a) from observations, (b) as predicted by the AWSdriven FLake-control, and (c) as predicted by FLake-ERA-Interim. The black line depicts the mixed layer depth (Sect. 2.3; weekly mean for the simulations). Note the different colour scaling in (c).

respectively). Especially the latter effect is potentially relevant, given the influence of large-scale climate oscillations such as the El Niño-Southern Oscillation (ENSO) on the regional climate (Plisnier et al., 2000) and the contrasting ENSO indices found for both periods (La Niña years versus El Niño years). Further research will aim at quantifying uncertainties associated with lake-wide evaporation estimates for tropical lakes.

Results from the AWS control simulations show that FLake successfully incorporates these differences between the sites, since the model, through the differences in forcing and configuration, successfully represents the thermal structure of both Lake Kivu and Lake Tanganyika and discerns the differences between the two basins within Lake Tanganyika.

\subsection{Sensitivity study}

Originally designed for implementation within NWP systems or climate models, FLake requires information on lake depth and water transparency (downward light attenuation coefficient) for each lake within its domain. But despite recent efforts to gather and map lake depth on a global scale (Kourzeneva, 2010; Kourzeneva et al., 2012a), in East Africa information on lake depth and water transparency is only available for the largest lakes, adding uncertainty to FLake's outcome when it is applied to the entire region. Furthermore, the effect of the forcing data source - e.g. originating from an AWS, a reanalysis product or RCM output - and its associated quality might significantly affect the outcome of a simulation. As RCMs and standalone lake models are being applied to increasingly remote lakes, the need to consider this data quality issue grows (Martynov et al., 2010). Finally, in 


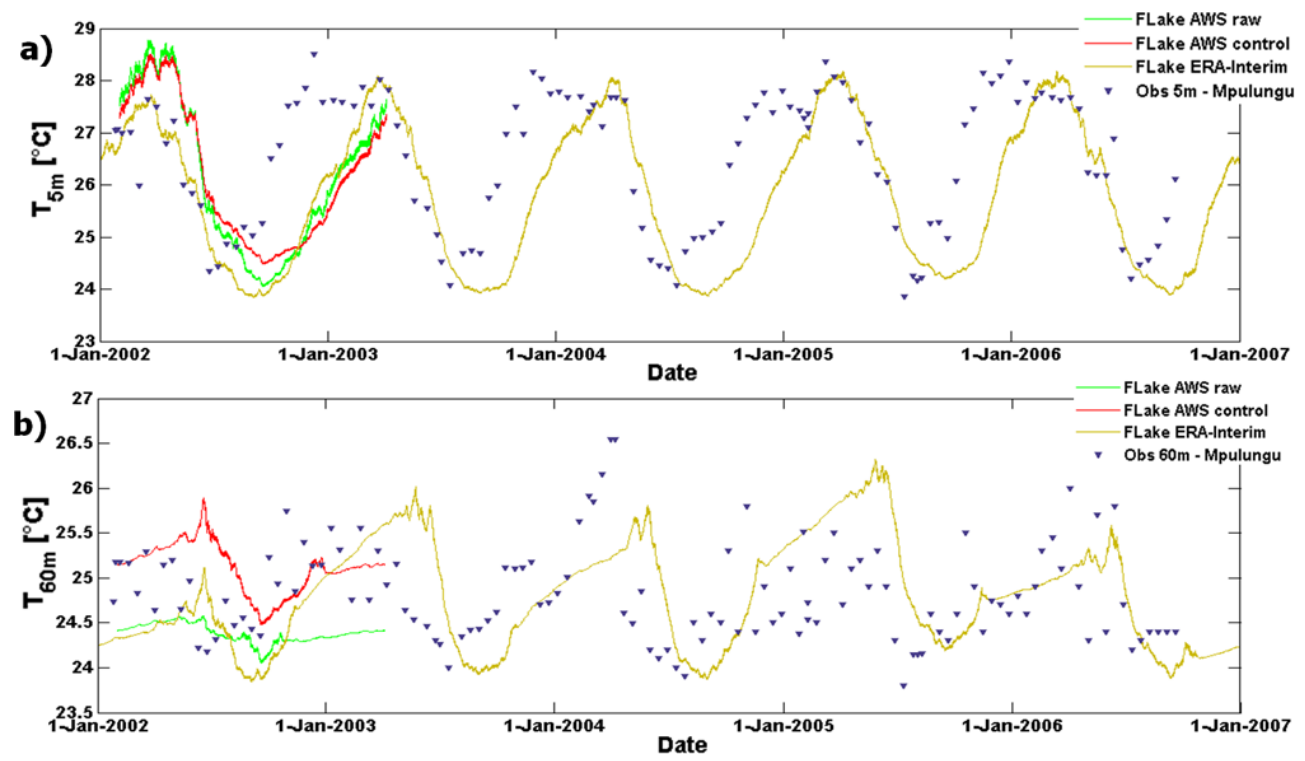

Fig. 8. Modelled and observed temperature evolution at Mpulungu (southern basin of Lake Tanganyika) at (a) $5 \mathrm{~m}$, and (b) $60 \mathrm{~m}$ depth.

the absence of initialisation data, several approaches to lake temperature initialisation and spin-up have been applied in the past (Kourzeneva et al., 2008; Mironov et al., 2010; Balsamo et al., 2012; Hernández-Díaz et al., 2012; Rontu et al., 2012). Hence, a systematic study of the sensitivity of the model to different sources of error is appropriate. Hereafter, results of FLake's sensitivity to variations in (i) external parameters, (ii) meteorological forcing data, and (iii) temperature initialisation are presented. Note that each set of the following tests was conducted starting from the Lake Kivu control simulation (Sect. 3.1). However, the same experiments have been conducted for Kigoma and Mpulungu as well, and revealed very similar responses to the imposed changes.

\subsubsection{External parameters}

The first set of model sensitivity tests was conducted to investigate FLake's sensitivity to changes in the model's external parameters. Using a set of four model efficiency scores (Sect. 2.4), the impact of setting the model lake depth to a relatively shallow $30 \mathrm{~m}$ (SHA) or a relatively deep $120 \mathrm{~m}$ (DEE), and setting $k$ to the highest (KHI) or lowest (KLO) observed value at Ishungu (Table 2) was quantified. $\sigma_{T}$, $\mathrm{RMSE}_{\mathrm{c}}$ and $r$ calculated at three depths $(5 \mathrm{~m}, 30 \mathrm{~m}$ and $60 \mathrm{~m}$, respectively) are visualised in Taylor diagrams (Fig. 10). Furthermore, note that we also investigated the sensitivity of FLake to changes in the fetch, by conducting a set of simulations with the fetch varying between 1 and $100 \mathrm{~km}$, respectively (the value in all other simulations is $10 \mathrm{~km}$ ). It was found, however, that for Lake Kivu, FLake exhibits only little sensitivity to modifications in this parameter.
At $5 \mathrm{~m}$ depth, the different sensitivity experiments produce similar values for $\mathrm{RMSE}_{\mathrm{c}}, r$, and BSS (not shown). The only score for which the control simulation outcompetes the other members is $\sigma_{T}$, suggesting that in this case seasonal temperature variability is closest to reality. At $30 \mathrm{~m}$, some changes to this pattern can already be noticed (Fig. 10b). Most notably, for the SHA test case predictive skill significantly decreases. For this test, FLake predicts fully mixed conditions down to $30 \mathrm{~m}$ most of the time, except during the 2005, 2007 and 2009 rainy seasons, when mixing down to $10 \mathrm{~m}$ is predicted. However, only at $60 \mathrm{~m}$ do the differences fully emerge, with a clear reduction in predictive skill for the simulations with $k$ decreased (increased) to the lowest (highest) observed values at Ishungu. Higher water transparency leads to deeper mixing, as solar radiation penetrates down to the interface between mixed layer and thermocline and therewith enhances $h_{\mathrm{ML}}$. Note that for the more transparent Lake Tanganyika, FLake's sensitivity to changes in $k$ is even more important. There, a change of less than $1 \sigma$ away from the average observed $k$ already led to a switch from permanently mixed conditions to a continuously stratified regime.

\subsubsection{Forcing data}

In a second set of experiments, FLake's sensitivity to changes in forcing variables was investigated. Starting from the control simulation at Ishungu, values for $T, \mathrm{RH}, f f$ and $\mathrm{LW}_{\text {in }}$ were varied in pairs between bounds $o_{i}-2 \sigma$ to $o_{i}+2 \sigma$, with $o_{i}$ the actual observed value at time step $i$, and $\sigma$ the standard deviation of a given variable (see also Thiery et al., 2012). Standard deviations for $T, \mathrm{RH}, \mathrm{ff}$ and $\mathrm{LW}_{\text {in }}$ are $2.4^{\circ} \mathrm{C}, 14 \%, 1.7 \mathrm{~m} \mathrm{~s}^{-1}$ and $18 \mathrm{~W} \mathrm{~m}^{-2}$, respectively. The perturbation increment was $0.4 \times \sigma$ in each experiment. The 

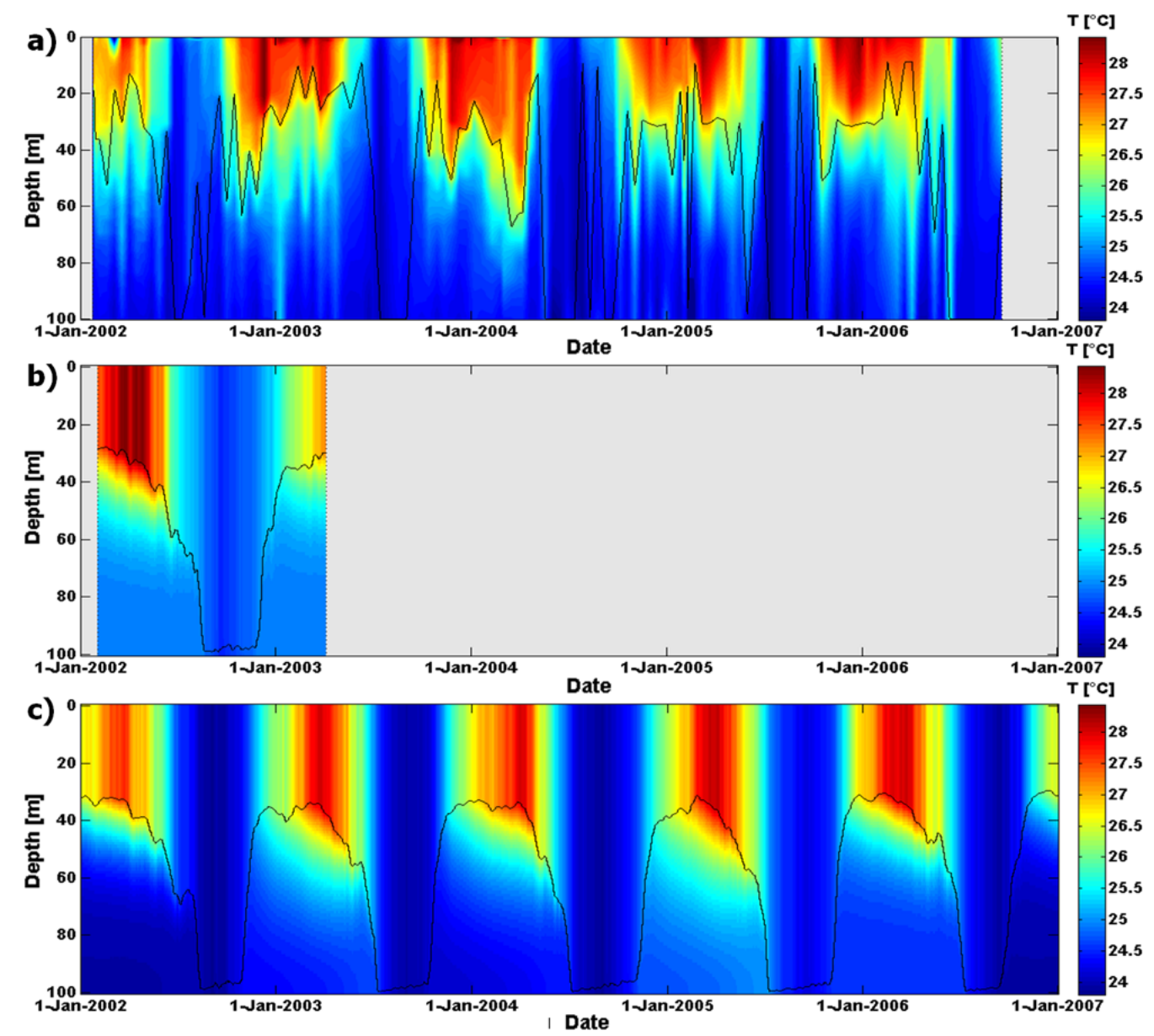

Fig. 9. Lake water temperatures $\left({ }^{\circ} \mathrm{C}\right)$ at Mpulungu (southern basin of Lake Tanganyika) (a) from observations, (b) as predicted by the AWSdriven FLake-control, and (c) as predicted by FLake-ERA-Interim. The black line depicts the mixed layer depth (Sect. 2.3; weekly mean for the simulations). Results in (c) were obtained with $k=0.09 \mathrm{~m}^{-1}$.

vertically averaged BSS for water temperature calculated per metre depth for 2003-2011 after this pairwise perturbation (Fig. 11) allowed for the selection of the main environmental variables controlling $h_{\mathrm{ML}}$ in tropical conditions. Sensitivity experiments for $p$ and $\mathrm{SW}_{\mathrm{in}}$ are not shown, the former since FLake was found to be not sensitive to this variable, the latter since its high standard deviation $\left(252 \mathrm{~W} \mathrm{~m}^{-2}\right)$ led to unrealistic perturbations. To overcome this issue, an additional experiment was conducted wherein the $\mathrm{SW}_{\text {in }}$ and $\mathrm{LW}_{\text {in }}$ time series were perturbed by the respective standard deviations of their daily means $\left(\sigma_{\mathrm{dm}}\right.$, with values of $35 \mathrm{~W} \mathrm{~m}^{-2}$ and $12 \mathrm{~W} \mathrm{~m}^{-2}$, respectively; Fig. 12).

For Lake Kivu, FLake results reveal a marked sensitivity to variations in wind speed (Fig. 11a and b). Generally, when wind velocities increase (decrease), mechanical mixing reaches deeper (less deep) into the lake, causing a cooling (warming) of the mixed layer for the same energy budget. For Lake Kivu, however, at some point the increased wind velocity provokes a regime switch from seasonally mixed conditions to (almost) permanently mixed conditions. This switch, illustrated by the sharp decrease in BSS in Fig. 11a, b along the $f f$ axis, is already reached before $f f$ is enhanced by $0.4 \sigma$. Similarly, only slightly decreasing $f f$ already leads to a sharp switch to the permanently stratified regime. Increasing (decreasing) $T$ and RH by their respective $\sigma$ equally contributes to higher (lower) mixed layer temperatures, which in turn enhances (reduces) stratification (Fig. 11c). Again, the vertically averaged BSS depicts the switch to both other regimes: a sharp transition to permanent stratification for increased $T$ and RH and a gradual transition to fully mixed conditions for lower $T$ and RH. A similar sensitivity is found when testing for $\mathrm{LW}_{\mathrm{in}}$, although FLake seems less sensitive to variations in this variable (Fig. 11d). When comparing $\mathrm{SW}_{\text {in }}$ and $\mathrm{LW}_{\text {in }}$ for perturbations of the order of their respective $\sigma_{\mathrm{dm}}$ (Fig. 12), it can be noted that fairly large perturbations are needed to provoke a regime switch, and that such a switch is provoked more easily by modifying $\mathrm{SW}_{\text {in }}$ than $\mathrm{LW}_{\text {in }}$ by their respective $\sigma_{\mathrm{dm}}$. Note that when combined in pairs, errors may compensate each other and still generate adequate model predictions, as is the case when, e.g. simultaneously reducing $f f$ and $T$ by 

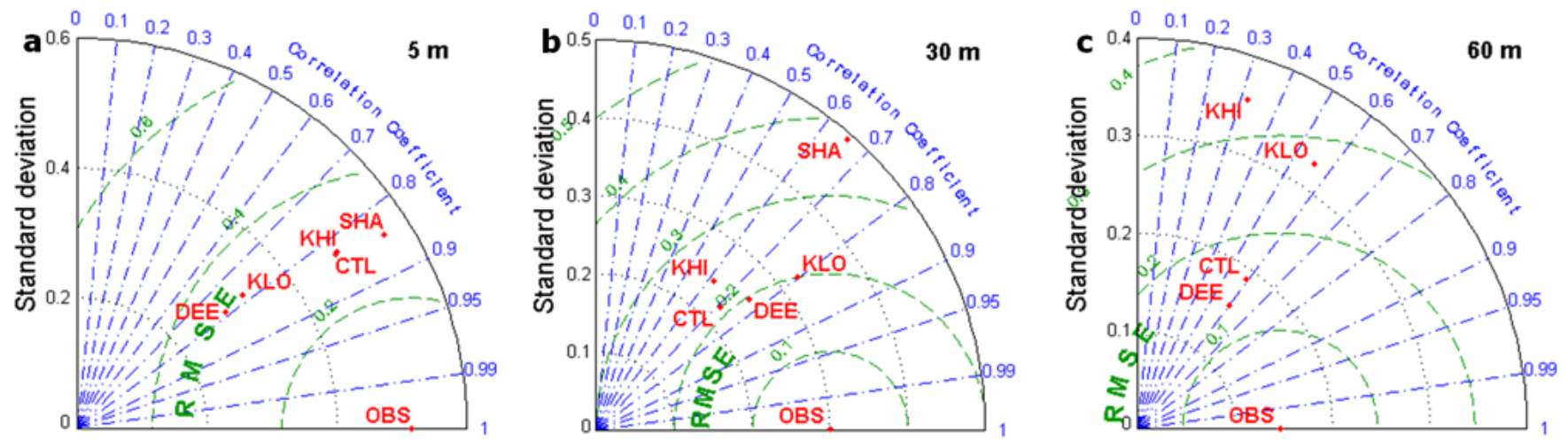

Fig. 10. Taylor diagram indicating model performance for water temperature at (a) $5 \mathrm{~m}$, (b) $30 \mathrm{~m}$ and (c) $60 \mathrm{~m}$ depths for different external parameter values at Ishungu (January 2003-December 2011). Standard deviation $\sigma_{T}\left({ }^{\circ} \mathrm{C}\right.$; radial distance), centred root mean square error $\mathrm{RMSE}_{\mathrm{c}}\left({ }^{\circ} \mathrm{C}\right.$; distance apart) and Pearson correlation coefficient $r$ (azimuthal position of the simulation field) were calculated from the observed T-profile interpolated to a regular grid $(1 \mathrm{~m}$ increment) and corresponding midday FLake profile. OBS: observations, CTL: control, SHA (DEE): model lake depth set to and $30 \mathrm{~m}(120 \mathrm{~m}), \mathrm{KHI}(\mathrm{KLO})$ : downward light attenuation coefficient $k$ set to the highest (lowest) observed value at Ishungu. Note that model performance indicators at $60 \mathrm{~m}$ cannot be calculated for the SHA integration.

one respective $\sigma$, or increasing $\mathrm{LW}_{\text {in }}$ while decreasing $\mathrm{RH}$ by one respective $\sigma$.

Finally, for each variable in this experiment, one can also derive an uncertainty range for which FLake predicts the correct mixing regime. With a vertically averaged BSS threshold set to -20 , the range width of wind velocities for which a correct mixing regime is predicted is $0.7 \mathrm{~m} \mathrm{~s}^{-1}$ around the actual observed values of the control run (Fig. 11a). For RH, $T, \mathrm{LW}_{\text {in }}$ and $\mathrm{SW}_{\text {in }}$, this range is $17 \%, 2.0^{\circ} \mathrm{C}, 50 \mathrm{~W} \mathrm{~m}^{-2}$ and $42 \mathrm{~W} \mathrm{~m}^{-2}$, respectively. While for the latter four variables, collecting in situ measurements within these uncertainty bounds is feasible, clearly, the room for manoeuvre in case of wind velocity measurements is very small. Consequently, the need for reliable wind velocities is critical to have FLake predicting the right mixing conditions over deep tropical lakes. Note that this is also the reason why wind speed was selected as the forcing variable to correct (Sect. 2.4). In return, when the same computation is conducted for the $5 \mathrm{~m}$ BSS instead of the vertically averaged BSS, the narrow band widens to $3.4 \mathrm{~m} \mathrm{~s}^{-1}$ (even with a $5 \mathrm{~m}$ BSS threshold set to only -2 , the acceptable uncertainty range is still $2.0 \mathrm{~m} \mathrm{~s}^{-1}$ ). Thus, in cases where the primary interest of the FLake application is the correct representation of near-surface water temperatures, the need for very high accuracy wind velocity measurements becomes less pressing.

This has implications for the applicability of FLake to the study of tropical lake-climate interactions. When FLake is interactively coupled to an atmospheric model, it may very well be that, e.g. the near-surface wind velocities serving as input to FLake will not fall within the narrow range for which it predicts a correct mixing regime. However, the only FLake variable which directly influences the atmospheric boundary layer is $T_{\mathrm{ML}}$, the variable from which the exchange of water and energy between the lake and the atmosphere are computed. In this study, $T_{\mathrm{ML}}$ predictions were found to be robust, even when modelled $T_{\mathrm{BOT}}$ values are biased. We may therefore suppose that for tropical conditions, a coupled model system will not be much affected by the strong sensitivity of FLake's deepwater temperatures to, for instance, wind speed values.

\subsubsection{Initial conditions}

The third set of experiments at Lake Kivu was designed to test the model to different initial conditions. In the control simulation, FLake was initialised with the average mixed layer, total water column and bottom temperatures calculated from the January CTD profiles $(n=14)$, after which spinup cycles were repeated until convergence is reached. Sensitivity experiments encompassed a simulation with the same initialisation but excluding spin-up (CES), a fully mixed (i.e. down to $60 \mathrm{~m}$ depth) water column initialisation including (MIS) or excluding spin-up (MES), and a stratified water column excluding spin-up (SES). By setting the initial mixed layer depth to $60 \mathrm{~m}$ and the lake water temperature to $28^{\circ} \mathrm{C}$, full mixing was imposed, whereas permanently stratified conditions were obtained by setting the initial mixed layer depth to $8 \mathrm{~m}, T_{\mathrm{ML}}$ to $23.5^{\circ} \mathrm{C}$ and $T_{\text {bot }}$ to $4{ }^{\circ} \mathrm{C}$ (comparable to Hernández-Díaz et al., 2012; Martynov et al., 2012). Note that a stratified initialisation including spin-up is omitted, since downward heat transport within the thermocline can only occur through molecular diffusion in this case, and hence would require millennia-scale spin-up time. Again, $\sigma_{T}, \mathrm{RMSE}_{\mathrm{c}}$, and $r$ were calculated and visualised for three depths (Fig. 13).

First, it can be noted that omitting spin-up in the optimal simulation (CES) has only limited, though negative, influence on the predictive skill. This shows that when a reliable initial CTD profile is available, spin-up has some, but 

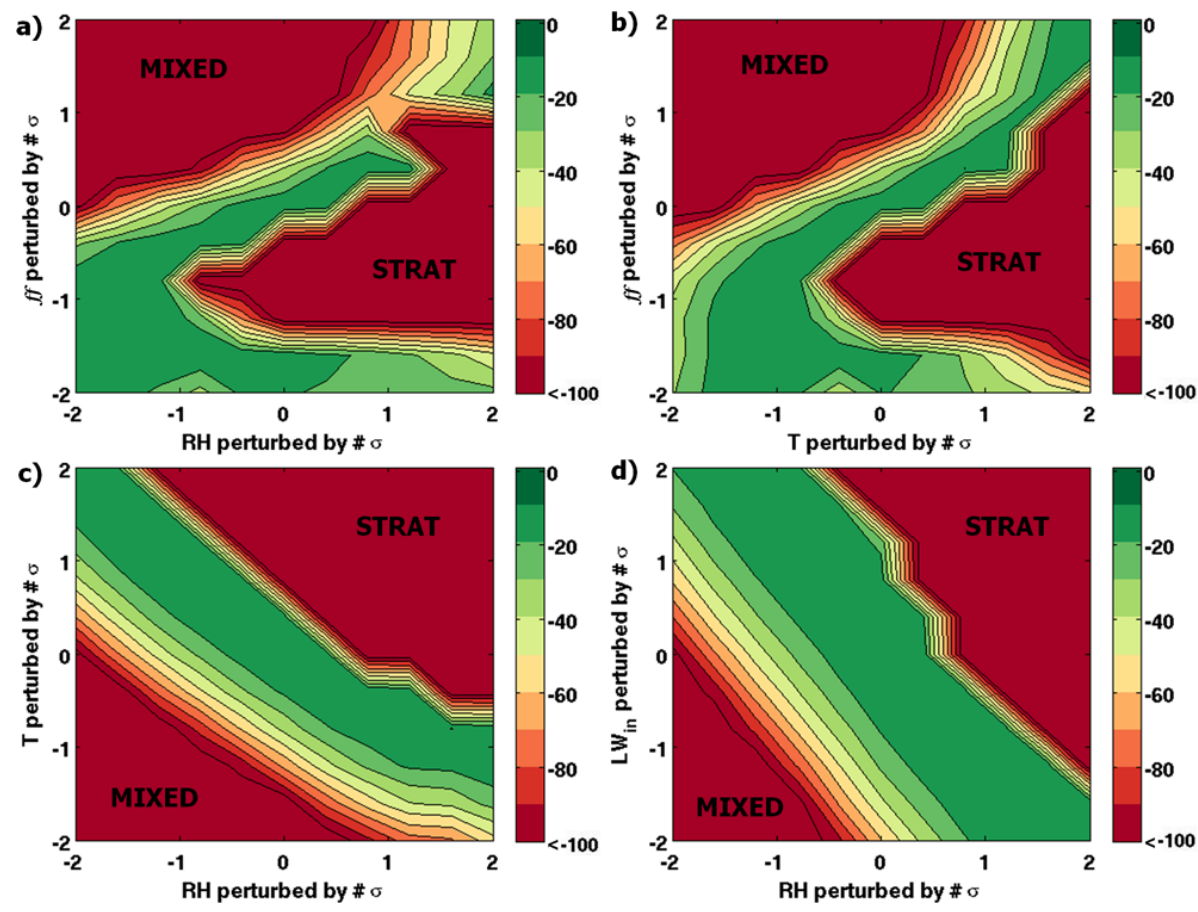

Fig. 11. Vertically averaged Brier Skill Scores (BSS) of water temperature profiles $(0-60 \mathrm{~m} ; 1 \mathrm{~m}$ vertical increment) at Ishungu from 4 sensitivity experiments, wherein pairs of forcing variables recorded at AWS 1 were perturbed by proportions of their respective standard deviations $\sigma$. Perturbed forcing variables are wind velocity ( $f f$ ), Relative humidity (RH), air temperature $(T)$ and incoming long-wave radiation $\left(\mathrm{LW}_{\mathrm{in}}\right)$. Generally, values for BSS range from +1 (perfect prediction) to $-\infty$ (no relation between observation and prediction). Here, BSS below -100 are set to -100 . Permanently stratified (STRAT) and fully mixed conditions down to $60 \mathrm{~m}$ (MIXED) are indicated.

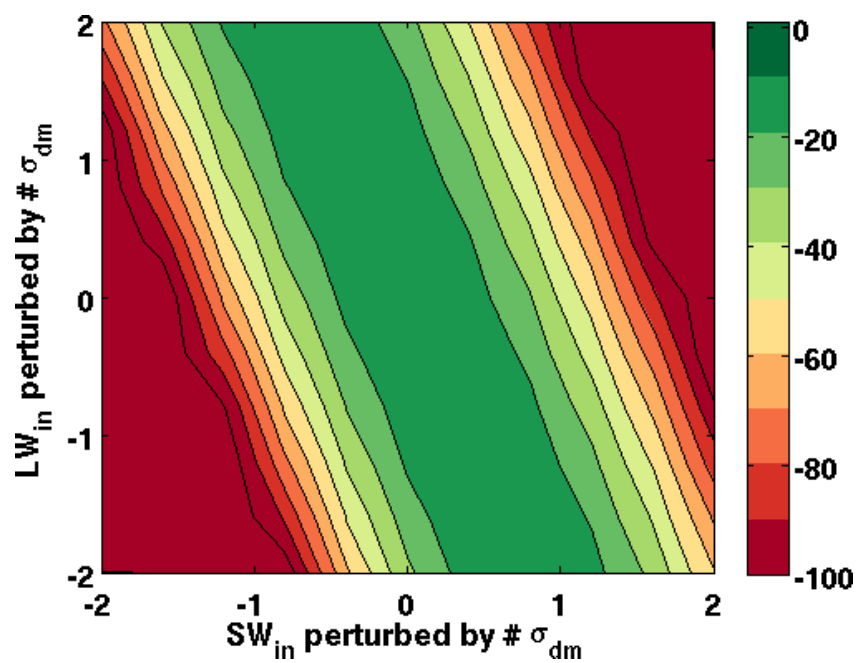

Fig. 12. Vertically averaged Brier Skill Scores (BSS) of water temperature profiles $(0-60 \mathrm{~m} ; 1 \mathrm{~m}$ vertical increment) at Ishungu from a set of simulations with $\mathrm{SW}_{\text {in }}$ and $\mathrm{LW}_{\text {in }}$ perturbed by proportions of their respective standard deviations of daily mean values $\left(\sigma_{\mathrm{dm}}\right)$.

only little added value. More interestingly, however, is the fact that a fully mixed and artificially warm initialisation with spin-up (MIS) succeeds very well in reproducing the thermal structure of Lake Kivu. Within 9 spin-up years, the complete mixing allows for an efficient heat release until the regime switches to the expected pattern. Since the model is allowed to spin-up until convergence is reached, the selection of the initial water column temperature does not influence the model performance, as long as it is chosen artificially warm. However, without spin-up (MES), this advantage vanishes and results have limited skill, since the lake has been initialised too warm. Alternatively, when offline spinup of lake temperatures is not feasible within the coupled model system, imposing permanently stratified conditions by means of a $4{ }^{\circ} \mathrm{C}$ lake bottom (SES) becomes an option, given the acceptable results near the lake surface even though the thermal structure is not reproduced. Note that this was the approach adopted for the CORDEX-Africa simulations conducted with the Canadian Regional Climate Model version 5 (Hernández-Díaz et al., 2012; Martynov et al., 2012). Hence, for coupled FLake-atmosphere simulations over regions with no initialisation information available, a fully mixed, artificially warm initialisation appears to be the best option, but only if offline lake temperature spin-up is applied; otherwise an imposed, permanently stratified regime is to be preferred.

\subsection{Mixing physics at Lake Kivu}

Studying the seasonal variations in the near-surface meteorological conditions and in the surface energy balance of 

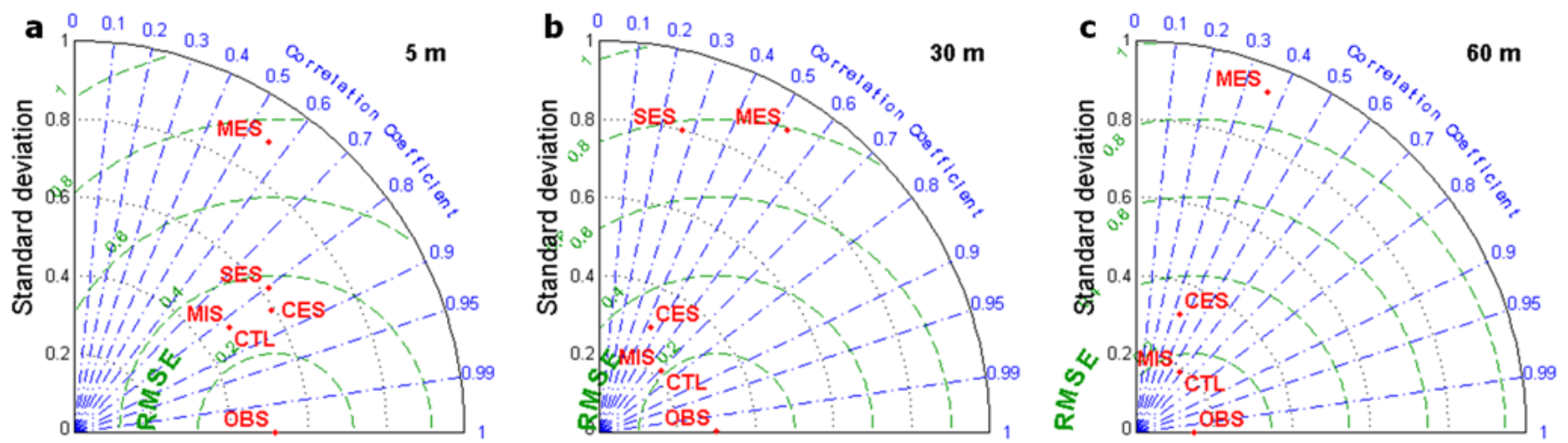

Fig. 13. Taylor diagram indicating model performance for water temperature at (a) $5 \mathrm{~m}$, (b) $30 \mathrm{~m}$ and (c) $60 \mathrm{~m}$ depths for different initial conditions at Ishungu (January 2003-December 2011). OBS: observations, CTL: control, CES: control excluding spin-up, SES: stratified excluding spin-up, MIS (MES): mixed warm initialisation including (excluding) spin-up. Note that SES is omitted at $60 \mathrm{~m}$ given its strong deviation from observations there.

the Ishungu control experiment allows us to attribute the seasonal mixing cycle for Lake Kivu. On the one hand, even though $\mathrm{ff}$ depicts some seasonality (Fig. 14a), neither ff nor $T$ influence the seasonality of the mixed layer depth at Ishungu. First, a comparative histogram of corrected $f f$ binned per month $\left(1 \mathrm{~m} \mathrm{~s}^{-1}\right.$ bin width; not shown) reveals that the probability of occurrence of stronger winds $\left(f f>5 \mathrm{~m} \mathrm{~s}^{-1}\right)$ is lower from April to July, adding to the hypothesis that higher wind velocities are not responsible for the deepening mixed layer depth during the dry season. This is confirmed by FLake, who attributes the mixed layer deepening at the start of the dry season to convection rather than winddriven mixing. Moreover, when conducting the Ishungu control simulation with the seasonality removed from $f f$, the predicted water temperatures are almost identical to the control simulation. This indicates that the $f f$ seasonality also has no major influence on the convective-driven mixing.

On the other hand, in contrast to ff and $T, \mathrm{RH}$ and $\mathrm{LW}_{\text {in }}$ both show a clear seasonality, with 3-monthly averages $13 \%$ and $11 \mathrm{~W} \mathrm{~m}^{-2}$, respectively, lower for the June-August period compared to December-February period. Their monthly average values show that the seasonal $\mathrm{RH}$ cycle lags the $\mathrm{LW}_{\text {in }}$ cycle by about one month, but they confirm the strong drop during the main dry season (Fig. 14b). Here, two effects enforce each other to reduce the amount of energy available to stratify the lake surface. First, as a consequence of reduced cloudiness during the dry season, less thermal radiation reaches the surface. This, in turn, causes a higher upward net long-wave radiation flux $\left(\mathrm{LW}_{\text {net }}\right)$ from May to July (Fig. 15). Second, more importantly, while a moisture climate close to saturation inhibits significant evaporation throughout most of the year, the RH drop during the dry season opens a larger potential to evaporation. This effect can be noted in the monthly average anomalies of the surface energy balance components, wherein the LHF shows a marked positive anomaly in months with low RH (Fig. 15). The energy
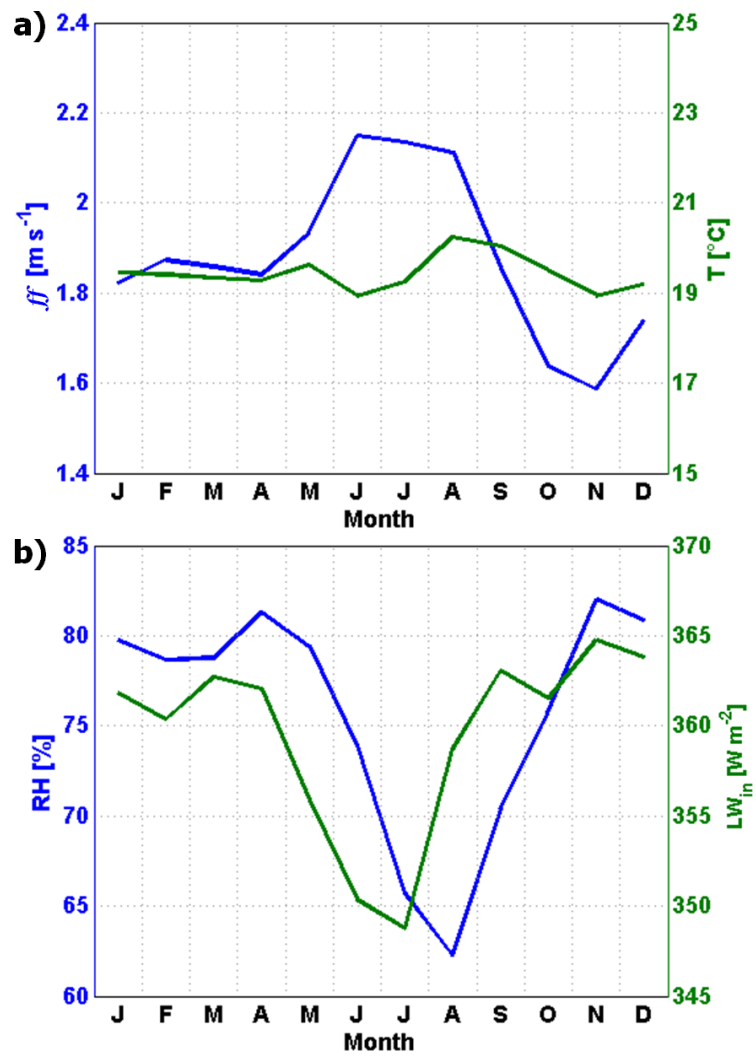

Fig. 14. Monthly averages for 2003-2011 of (a) wind velocity ff $\left(\mathrm{m} \mathrm{s}^{-1}\right)$ and air temperature $T\left({ }^{\circ} \mathrm{C}\right)$; (b) relative humidity $\mathrm{RH}$ (\%) recorded at Automatic Weather Station (AWS) 1 and incoming long-wave radiation $\mathrm{LW}_{\text {in }}\left(\mathrm{W} \mathrm{m}^{-2}\right)$ from ERA-Interim. Note the different $y$ axes increments.

consumed for evaporating is no longer available to heat the water surface. Thus, lower thermal radiation input and especially enhanced evaporation cause a significant reduction in the amount of energy available to heat near-surface waters. 


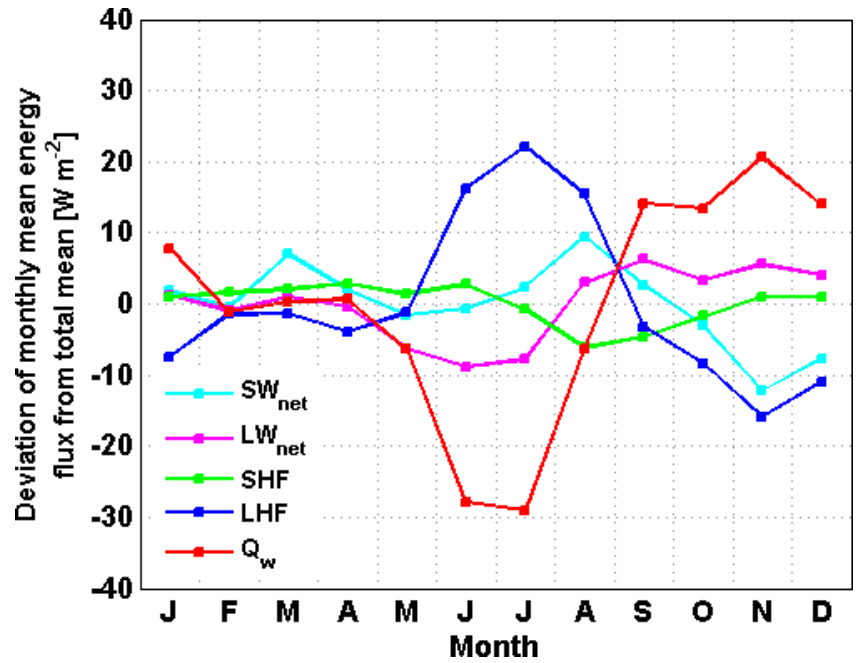

Fig. 15. Deviation of the monthly average of the surface energy balance components from its long-term mean $\left(\mathrm{W} \mathrm{m}^{-2}\right)$ at Ishungu, 2003-2011, calculated by FLake's surface flux routines. Components are net short-wave radiation $\left(\mathrm{SW}_{\text {net }}\right)$, net long-wave radiation $\left(\mathrm{LW}_{\text {net }}\right)$, sensible heat flux (SHF), latent heat flux (LHF) and subsurface conductive heat flux $(Q)$.

To compensate for this surface heat deficit, the upward subsurface conductive heat flux enhances, in turn generating a drop in the mixed layer temperature.

From mid-June onwards, near-surface water temperatures become low enough for the deep mixing to set in. Near the end of the dry season, from mid-August onwards, evaporation rates dramatically drop, causing the warming of surface waters from mid-September forward. Note that whereas enhanced solar radiation penetration into the lake is absent during the first phase of the dry season, near the end it slightly contributes to the restoration of surface stratification (Fig. 15). Overall, monthly variations in downward shortwave radiation $\left(\mathrm{SW}_{\text {in }}\right)$ seem to have only little effect on the mixed layer seasonality. Possibly, the interplay of astronomic short-wave radiation variability (with less short-wave radiation reaching the top of the atmosphere during the dry seasons) and seasonally varying cloud properties (Capart, 1952) balances out the amount of short-wave radiation reaching the surface on monthly timescales.

\section{Discussion and conclusions}

In general, this study shows that the thermal structure of the mixed layer and thermocline of two African Great Lakes can be reproduced by the FLake model. In particular, the seasonality of the near-surface water temperatures of Lake Kivu and Lake Tanganyika is well captured by the AWSdriven simulations when choosing appropriate values for the wind speed correction factor and $k$ within their uncertainty range. Moreover, FLake was found capable of reproducing the observed interannual variability, as well as the observed differences between the three sites. The spatial variability is accounted for through varying lake characteristics and meteorological conditions associated with different surface altitude and distance from the equator. At Ishungu, a study of the near-surface meteorology and surface heat balance was used to attribute seasonal mixing cycle of Lake Kivu. Rather than seasonal variations in wind velocity or air temperature, the marked dry season decrease of the incoming long-wave radiation and, especially, relative humidity with an associated evaporation peak, reduce the amount of energy available to induce surface stratification.

The near-surface water temperatures were found to be quite robust to changes in the model configuration. If the observed mixing regime is not reproduced, $5 \mathrm{~m}$ temperature predictions deteriorate compared to the control integration, but are relatively little affected. Hence, FLake can be considered an appropriate tool to study the climatic impact of lakes in the region of the African Great Lakes. In contrast, an accurate representation of the thermal structure of the mixed layer and thermocline depends strongly on the reliability of meteorological forcing data and a correct choice of model lake depth and water transparency. Slight differences in external parameters, and uncertainties associated with the meteorological forcing data (for instance related to measurement or atmospheric model uncertainty, or to the representativity of the data for over-lake conditions) may already lead to a switch from the observed regime of seasonal mixed layer deepening to either the permanently stratified or the fully mixed regime.

One important reason for this delicate balance found at Lake Kivu is the absence of an abyssal layer in FLake. In reality, the abyssal layer acts as a heat reservoir which buffers potential changes in bottom temperature. FLake, on the contrary, assumes a zero heat flux at the water-sediment interface (sediment routine switched off) or at the lower bound of the active sediment layer (sediment routine switched on). In cases where an artificial lake depth is set, this assumption can lead to unrealistic temperature fluctuations near the bottom. Hence, a future development could be to include an abyssal layer in FLake (Mironov et al., 2010).

A second issue is the reliability of water transparency values. Even in more studied areas, information on the spatial and temporal variability of water transparency is mostly lacking (Kirillin, 2010; Kourzeneva et al., 2012b; Rontu et al., 2012). Therefore, the first need is to collect more observations of $k$ and to gain more insight into the relationship between water transparency and seasonal mixing cycles in deep tropical lakes. In the future, FLake could then also be adapted to account for these seasonal fluctuations in $k$.

When applying FLake over regions containing warm deep lakes, values for the external parameters thus need to be considered carefully. This is especially true when FLake is coupled to NWP, RCM or GCM models, since the meteorological forcing data are potentially biased in that case. 
When setting up a climate or NWP simulation with interactive lakes, moreover, no information on the lake's initial conditions is available. In that respect, this study clearly shows that it is advisable to initialise all lakes with an artificially warm, uniform temperature and to allow for a considerable offline spin-up of the lake module. When such an offline lake spin-up is not feasible, initialising FLake with stratified conditions and an artificially low bottom temperature of $4{ }^{\circ} \mathrm{C}$ is to be preferred.

To conclude, the goal of this study was to assess the quality of lake temperature predictions by FLake when applied to tropical lakes. This was done through a number of simulations for three locations in the African Great lakes region: Ishungu (Lake Kivu), Kigoma (northern basin of Lake Tanganyika) and Mpulungu (southern basin of Lake Tanganyika). Results show that FLake is able to well represent the mixing regime at these different locations, however only when the model was carefully configured and allowed to spin-up over a considerable period. When input data quality is an issue, or the model is poorly configured, model results tend to deviate from observations towards the deep in large tropical lakes.

\section{Code availability}

FLake is freely available under the terms of the GNU Lesser General Public License (http://www.gnu.org/licenses/lgpl. $\mathrm{html})$. The model source code, external parameter data sets and a comprehensive model description can be obtained from the official FLake website (http://www.lakemodel.net), along with pre-processed meteorological forcing for several test cases.

\section{Appendix A}

Table A1. Acronyms and variable names

\begin{tabular}{|c|c|}
\hline AWS & Automatic Weather Station \\
\hline BSS & Brier Skill Score [] \\
\hline CORDEX & $\begin{array}{l}\text { Coordinated Regional climate Downscaling } \\
\text { Experiment }\end{array}$ \\
\hline COSMO & Consortium for Small-scale Modeling \\
\hline control & FLake simulation with $f f$ and $k$ corrected \\
\hline$C_{T}$ & $\begin{array}{l}\text { Shape factor with respect to the temperature } \\
\text { profile in the thermocline [] }\end{array}$ \\
\hline CES & Same as control, but excluding spin-up \\
\hline CTD & Conductivity-Temperature-Depth cast \\
\hline$d d$ & Wind direction $\left[{ }^{\circ}\right]$ \\
\hline DEE & $\begin{array}{l}\text { Same as control, but with lake depth set to } \\
120 \mathrm{~m}\end{array}$ \\
\hline ENSO & El Niño-Southern Oscillation \\
\hline
\end{tabular}

ERA-Interim Reanalysis product from January 1979 onward, produced by the European Centre for Medium-Range Weather Forecasts

ff Wind velocity $\left[\mathrm{m} \mathrm{s}^{-1}\right]$

FLake $\quad$ Freshwater Lake model

GCM General Circulation Model

$h_{\mathrm{ML}} \quad$ Mixed layer depth [m]

ITCZ Intertropical Convergence Zone

$k$

Downward light attenuation coefficient $\left[\mathrm{m}^{-1}\right]$

KHI Same as control, but with $k$ set to $0.46 \mathrm{~m}^{-1}$

KLO Same as control, but with $k$ set to $0.15 \mathrm{~m}^{-1}$

LHF Latent heat flux $\left[\mathrm{W} \mathrm{m}^{-2}\right]$

$\mathrm{LW}_{\text {in }} \quad$ Downward long-wave radiation $\left[\mathrm{W} \mathrm{m}^{-2}\right]$

$\mathrm{LW}_{\text {net }} \quad$ Net long-wave radiation $\left[\mathrm{W} \mathrm{m}^{-2}\right.$ ]

MES Same as control, but initially fully mixed and excluding spin-up

MIS Same as control, but initially fully mixed

$n \quad$ Number of observations []

NWP Numerical Weather Prediction

$p \quad$ Air pressure $[\mathrm{Pa}]$

$r \quad$ Pearson correlation coefficient []

raw FLake simulation with observed meteorology and $k$

RCM Regional Climate Model

RH Relative humidity [\%]

RMSE root mean square error [respective unit]

$\mathrm{RMSE}_{\mathrm{c}} \quad$ Centred root mean square error [respective unit]

$\sigma \quad$ Standard deviation [respective unit]

SES Same as control, but initially strongly stratified and excluding spin-up

SHA Same as control, but with lake depth set to $30 \mathrm{~m}$

$\mathrm{SW}_{\text {in }} \quad$ Downward short-wave radiation $\left[\mathrm{W} \mathrm{m}^{-2}\right]$

$T \quad$ Air temperature $\left[{ }^{\circ} \mathrm{C}\right]$

$T_{\mathrm{BOT}} \quad$ Bottom temperature $\left[{ }^{\circ} \mathrm{C}\right]$

$T_{\mathrm{ML}} \quad$ Mixed layer temperature $\left[{ }^{\circ} \mathrm{C}\right]$

$T_{\mathrm{MW}} \quad$ Water column average temperature $\left[{ }^{\circ} \mathrm{C}\right]$

$z_{\mathrm{sd}} \quad$ Disappearance depths of the Secchi disk [m]

Acknowledgements. We would like to thank Dmitrii Mironov for the helpful discussions on the modelling of tropical lakes and the Institut Supérieur Pédagogique in Bukavu for supplying data of AWS 1 . We also sincerely thank the Editor and the two anonymous reviewers for their constructive remarks. This work was financially and logistically supported by the Research Foundation - Flanders (FWO) and the Belgian Science Policy Office (BELSPO), the latter through the research projects EAGLES and CHOLTIC.

Edited by: J. Neal 


\section{References}

Akkermans, T., Lauwaet, D., Demuzere, M., Vogel, G., Nouvellon, Y., Ardö, J., Caquet, B., De Grandcourt, A., Merbold, L., Kutsch, W., and van Lipzig, N.: Validation and comparison of two soilvegetation-atmosphere transfer models for tropical Africa, J. Geophys. Res., 117, G02013, doi:10.1029/2011JG001802, 2012.

Akkermans, T., Thiery, W., and van Lipzig, N.: The regional climate impact of a realistic future deforestation scenario in the Congo Basin, J. Climate, doi:10.1175/JCLI-D-13-00361.1, 2014.

Alleman, L. Y., Cardinal, D., Cocquyt, C., Plisnier, P.-D., Descy, J.P., Kimirei, I., Sinyinza, D., and André, L.: Silicon Isotopic Fractionation in Lake Tanganyika and Its Main Tributaries, J. Great Lakes Res., 31, 509-519, 2005.

Anyah, R. O., Semazzi, F. H. M., and Xie, L.: Simulated Physical Mechanisms Associated with Climate Variability over Lake Victoria Basin in East Africa, Mon. Weather Rev., 134, 3588-3609, 2006.

Balsamo, G., Salgado, R., Dutra, E., Boussetta, S., and Stockdale, T.: On the contribution of lakes in predicting near-surface temperature in a global weather forecasting model, Tellus A, 64, 15829, doi:10.3402/tellusa.v64i0.15829, 2012.

Beadle, L. C.: The inland waters of Tropical Africa, An introduction to tropical limnology, Longman, London, United Kingdom, 475 pp., 1981.

Bonan, G. B.: Sensitivity of a GCM Simulation to Inclusion of Inland Water Surfaces, J. Climate, 8, 2691-2703, 1995.

Borgès, A. V., Abril, G., Delille, B., Descy, J.-P., and Darchambeau, F.: Diffusive methane emissions to the atmosphere from Lake Kivu (Eastern Africa), J. Geophys. Res., 116, G03032, doi:10.1029/2011JG001673, 2011.

Bultot, F.: Atlas climatique du bassin Congolais, vol 2: Les composantes du bilan d'eau, Publications de l'Institut National pour l'Étude Agronomique du Congo, Brussels, Belgium, 1971.

Capart, A.: Le milieu géographique et géophysique, Résultats scientifiques de l' exploration hydrobiologique du Lac Tanganyika (1946-1947), Royal Belgian Institute of Natural Sciences, Brussels, Belgium, 27 pp., 1952.

Coulter, G. W. (Ed.): Lake Tanganyika and its life, Oxford University Press, London, United Kingdom, 354 pp., 1991.

Darchambeau, F., Sarmento, H., and Descy, J.-P.: Primary production in a tropical large lake: The role of phytoplankton composition, Sci. Total Environ., 473, 178-188, 2014.

De Boor, C.: A Practical Guide to Splines, Applied Mathematical Sciences series, 27, Springer-Verlag, New York, 346 pp., 1978.

Dee, D. P., Uppala, S. M., Simmons, A. J., Berrisford, P., Poli P., Kobayashi, S., Andrae, U., Balmaseda, M. A., Balsamo, G., Bauer, P., Bechtold, P., Beljaars, A. C. M., van de Berg, L., Bidlot, J., Bormann, N., Delsol, C., Dragani, R., Fuentes, M., Geer, A. J., Haimberger, L., Healy, S. B., Hersbach, H., Hólm, E. V., Isaksen, L., Källberg, P., Köhler, M., Matricardi, M., McNally, A. P., Monge-Sanz, B. M., Morcrette, J.-J., Park, B.-K., Peubey, C., de Rosnay, P., Tavolato, C., Thépaut, J.-N., and Vitart, F.: The ERA-Interim reanalysis: Configuration and performance of the data assimilation system, Q. J. Roy. Meteor. Soc., 137, 553-597, 2011.

Degens, E. T., von Herzen, R. P., Wong, H.-K., Deuser, W. G., and Jannash, H. W.: Lake Kivu: Structure, Chemistry and Biology of an East African Rift Lake, Geol. Rundsch., 62, 245-277, doi:10.1007/BF01826830, 1973.
Doms, G. and Schättler, U.: A Description of the Nonhydrostatic Regional Model LM. Part 1: Dynamics and Numerics, German Weather Service, Offenbach am Main, Germany, 140 pp., 2002.

Doms, G., Förstner, J., Heise, E., Herzog, H.-J., Mironov, D., Raschendorfer, M., Reinhardt, T., Ritter, B., Schrodin, R., Schulz, J.-P., and Vogel, G.: A Description of the Nonhydrostatic Regional COSMO Model. Part 2: Physical Paramaterization, German Weather Service, Offenbach am Main, Germany, 161 pp., 2011.

Dutra, E., Stepanenko, V. M., Balsamo, G., Viterbo, P., Miranda, P. M. A., Mironov, D., and Schär, C.: An offline study of the impact of lakes on the performance of the ECMWF surface scheme, Boreal Environ. Res., 15, 100-112, 2010.

Giorgi, F., Jones, C., and Asrar, G. R.: Addressing climate information needs at the regional level: the CORDEX framework, WMO Bull., 58, 175-183, 2009.

Gourgue, O., Deleersnijder, E., Legat, V., Marchal, E., and White, L.: Free and forced thermocline oscillations in Lake Tanganyika, in: Factor separation in the atmosphere: applications and future prospects, edited by: Alpert, P. and Sholokhman, T., Cambridge University Press, Cambridge, United Kingdom, 146-162, 2011.

Hernández-Díaz, L., Laprise, R., Sushama, L., Martynov, A., Winger, K., and Dugas, B.: Climate simulation over CORDEX Africa domain using the fifth-generation Canadian Regional Climate Model (CRCM5), Clim. Dynam., 40, 1415-1433, doi:10.1007/s00382-012-1387-z, 2012.

Kirillin, G.: Modelling the impact of global warming on water temperature and seasonal mixing regimes in small temperature lakes, Boreal Environ. Res., 15, 279-293, 2010.

Kitaigorodskii, S. A. and Miropolskii, Yu. Z.: On the theory of the open ocean active layer, Izv. Atmos. Oceanic Phys., 6, 97-102, 1970.

Kourzeneva, E. V.: External data for lake parameterization in $\mathrm{Nu}-$ merical Weather Prediction and climate modelling, Boreal Environ. Res., 15, 165-177, 2010.

Kourzeneva, E. V., Samuelsson, P., Ganbat, G., and Mironov, D.: Implementation of Lake Model FLake in HIRLAM, HIRLAM Newsletter no 54, 54-61, 2008.

Kourzeneva, E. V., Asensio, H., Martin, E., and Faroux, S.: Global gridded dataset of lake coverage and lake depth for use in numerical weather prediction and climate modelling, Tellus A, 64, 15640, doi:10.3402/tellusa.v64i0.15640, 2012a.

Kourzeneva, E. V., Martin, E., Batrak, Y., and Le Moigne, P.: Climate data for parameterisation of lakes in $\mathrm{Nu}-$ merical Weather Prediction models, Tellus A, 64, 17226, doi:10.3402/tellusa.v64i0.17226, 2012b.

Lauwaet, D., van Lipzig, N. P. M., Van Weverberg, K., De Ridder, K., Goyens, C.: The precipitation response to the desiccation of Lake Chad, Q. J. Roy. Meteor. Soc., 138, 707-719, doi:10.1002/qj.942, 2011.

Martynov, A., Sushama, L., and Laprise, R.: Simulation of temperate freezing lakes by one-dimensional lake models: performance assessment for interactive coupling with regional climate models, Boreal Environ. Res., 15, 143-164, 2010.

Martynov, A., Sushama, L., Laprise, R., Winger, K., and Dugas, B.: Interactive Lakes in the Canadian Regional Climate Model, version 5: The Role of Lakes in the Regional Climate of North America, Tellus A, 64, 16226, doi:10.3402/tellusa.v64i0.16226, 2012. 
Mironov, D.: Parameterization of Lakes in Numerical Weather Prediction. Description of a Lake Model, COSMO Technical Report No. 11, German Weather Service, Offenbach am Main, Germany, 44 pp., 2008.

Mironov, D., Heise, E., Kourzeneva, E., Ritter, B., Schneider, N., and Terzhevik, A.: Implementation of the lake parameterisation scheme FLake into the numerical weather prediction model COSMO, Boreal Environ. Res., 15, 218-230, 2010.

Munk, W. H. and Anderson, E. R.: Notes on a theory of the thermocline, J. Marine Res., 7, 276-295, 1948.

Naithani, J., Deleersnijder, E., and Plisnier, P.-D.: Analysis of WindInduced Thermocline Oscillations of Lake Tanganyika, Environ. Fluid Mech., 3, 23-39, 2003.

Naithani, J., Darchambeau, F., Deleersnijder, E., Descy, J. P., and Wolanski, E.: Study of the nutrient and plankton dynamics in lake Tanganyika using a reduced-gravity model, Ecol. Model., 200, 225-233, 2007.

Nash, J. E. and Sutcliffe, J. V.: River flow forecasting through conceptual models part I - A discussion of principles, J. Hydrol., 10, 282-290, 1970 .

Nicholson, S. E.: A review of climate dynamics and climate variability in eastern Africa, in: The Limnology, Climatology and Paleoclimatology of the East African Lakes, edited by: Johnson, T. C. and Odada, E., Gordon \& Breach, Amsterdam, 25-56, 1996.

O'Reilly, C. M., Alin, S. R., Plisnier, P., Cohen, A. S., and McKee, B. A.: Climate change decreases aquatic ecosystem productivity of lake Tanganyika, Africa, Nature, 424, 766-768, 2003.

Plisnier, P.-D., Chitamwebwa, D., Mwape, L., Tshibangu, K., Langenberg, V., and Coenen, E.: Limnological annual cycle inferred from physical-chemical fluctuations at three stations of Lake Tanganyika, Hydrobiologia, 407, 45-58, 1999.

Plisnier, P.-D., Serneels, S., and Lambin, E. F.: Impact of ENSO on East African ecosystems: a multivariate analysis based on climate and remote sensing data, Global Ecol. Biogeogr., 9, 481497, 2000.

Plisnier, P.-D., Cornet, Y., Naithani, J., Deleersnijder, E., and Descy, J.-P.: Climate change impact on the sustainable use of Lake Tanganyika fisheries (CLIMFISH), Royal Museum for Central Africa, Tervuren, Belgium, BELSPO final report, 155 pp., 2007.

Raschendorfer, M.: The new turbulence parameterization of LM, German Weather Service, Offenbach am Main, Germany, COSMO Newsletter No. 1, 89-97, 2001.

Rontu, L., Eerola, K., Kourzeneva, E., and Vehviläinen, B.: Data assimilation and parametrisation of lakes in HIRLAM, Tellus A, 64, 17611, doi:10.3402/tellusa.v64i0.17611, 2012.

Salgado, R. and Le Moigne, P.: Coupling of the FLake model to the Surfex externalized surface model, Boreal Environ. Res., 15, 231-244, 2010.

Samuelsson, P., Kourzeneva, E., and Mironov, D.: The impact of lakes on the European climate as simulated by a regional climate model, Boreal Environ. Res., 15, 113-129, 2010.

Sarmento, H., Isumbishu, M., and Descy, J.-P.: Phytoplankton ecology of Lake Kivu (eastern Africa), J. Plankton Res., 28, 815-829, doi:10.1029/2004GC000892, 2006.

Sarmento, H., Darchambeau, F., and Descy, J.-P.: Phytoplankton of Lake Kivu, in: Lake Kivu: Limnology and biogeochemistry of a tropical great lake, edited by: Descy, J.-P., Darchambeau, F., and Schmid, M., Springer, Dordrecht, 67-83, 2012.
Savijärvi, H.: Diurnal winds around Lake Tanganyika, Q. J. Roy. Meteor. Soc., 123, 901-918, 1997.

Savijärvi, H. and Järvenoja, S.: Aspects of Fine-Scale Climatology Over Lake Tanganyika as Resolved by a Mesoscale Model, Meteorol. Atmos. Phys., 73, 77-88, 2000.

Schmid, A. and Wüest, A.: Stratification, Mixing and Transport Processes in Lake Kivu, in: Lake Kivu: Limnology and biogeochemistry of a tropical great lake, edited by: Descy, J.-P., Darchambeau, F., and Schmid, M., Springer, Dordrecht, 13-29, 2012.

Schmid, M., Halbwachs, M., Wehrli, B., and Wüest, A.: Weak mixing in Lake Kivu: New insights indicate increasing risk of uncontrolled gas eruption, Geochem. Geophy. Geosy., 6, Q07009, doi:10.1029/2004GC000892, 2005.

Schmid, M., Busbridge, M., and Wüest, A.: Double-diffusive convection in Lake Kivu, Limnol. Oceanogr., 55, 225-238, 2010.

Simmons, A., Uppala, S., Dee, D., and Kobayashi, S.: ERA-Interim: New ECMWF reanalysis products from 1989 onwards, European Centre for Medium-Range Weather Forecasts, Reading, UK, ECMWF Newsletter No. 110, 25-35, 2007.

Spigel, R. H. and Coulter, G. W.: Comparison of hydrology and physical limnology of the East African Great Lakes: Tanganyika, Malawi, Victoria, Kivu and Turkana (with references to some North American Great Lakes), in: The Limnology, Climatology and Paleoclimatology of the East African lakes, edited by: Johnson, T. C. and Odada, E., Gordon and Breach Publishers, Amsterdam, The Netherlands, 103-140, 1996.

Stenuite, S., Pirlot, S., Hardy, M. A., Sarmento, H., Tarbe, A. L., Leporcq, B., and Descy, J.-P.: Phytoplankton production and growth rate in Lake Tanganyika: evidence of a decline in primary productivity in recent decades, Freshwater Biol., 52, 2226-2239, doi:10.1111/j.1365-2427.2007.01829.x, 2007.

Stepanenko, V. M., Martynov, A., Jöhnk, K. D., Subin, Z. M., Perroud, M., Fang, X., Beyrich, F., Mironov, D., and Goyette, S.: A one-dimensional model intercomparison study of thermal regime of a shallow, turbid midlatitude lake, Geosci. Model Dev., 6, 1337-1352, doi:10.5194/gmd-6-1337-2013, 2013.

Taylor, K. E.: Summarizing multiple aspects of model performance in a single diagram, J. Geophys. Res., 106, 7183-7192, 2001.

Thiery, W., Gorodetskaya, I. V., Bintanja, R., Van Lipzig, N. P. M., Van den Broeke, M. R., Reijmer, C. H., and Kuipers Munneke, P.: Surface and snowdrift sublimation at Princess Elisabeth station, East Antarctica, The Cryosphere, 6, 841-857, doi:10.5194/tc-6841-2012, 2012.

Thiery, W., Stepanenko, V. M., Fang, X., Jöhnk, K. D., Li, Z., Martynov, A., Perroud, M., Subin, Z. M., Darchambeau, F., Mironov, D., and van Lipzig, N. P. M.: LakeMIP Kivu: Evaluating the representation of a large, deep tropical lake by a set of one-dimensional lake models, Tellus, Ser. A, 66, 21390, doi:10.3402/tellusa.v66.21390, 2014.

Verburg, P. and Antenucci, J. P.: Persistent unstable atmospheric boundary layer enhances sensible and latent heat loss in a tropical great lake: Lake Tanganyika, J. Geophys. Res., 115, D11109, doi:10.1029/2009JD012839, 2010.

Verburg, P. and Hecky, R. E.: Wind patterns, Evaporation and Related Physical Variables in Lake Tanganyika, East-Africa, J. Great Lakes Res., 29, 48-61, 2003.

Verburg, P. and Hecky, R. E.: The physics of warming of lake Tanganyika by climate change, Limnol. Oceanogr., 54, 2418-2430, 2009. 
Verburg, P., Hecky, R. E., and Kling, H.: Ecological Consequences of a Century of Warming in Lake Tanganyika, Science, 301, 505507, 2003.

Verburg, P., Antenucci, J. P., and Hecky, R. E.: Differential cooling drives large-scale convective circulation in Lake Tanganyika, Limnol. Oceanogr., 56, 910-926, doi:10.4319/lo.2011.56.3.0910, 2011.
Wilks, D. S.: Statistical methods in atmospheric sciences, International Geophysics Series, 100, Academic Press, Oxford, United Kingdom, 676 pp., 2005. 